\title{
Multi-Layer Artificial Neural Networks Based MPPT-Pitch Angle Control of a Tidal Stream Generator
}

\author{
Khaoula Ghefiri ${ }^{1,2, *(1)}$, Soufiene Bouallègue ${ }^{1}$, Izaskun Garrido ${ }^{2}$ (D) , Aitor J. Garrido ${ }^{2}$ and \\ Joseph Haggège ${ }^{1}$ \\ 1 Laboratory of Research in Automatic Control-LA.R.A, National Engineering School of Tunis (ENIT), \\ University of Tunis El Manar, BP 37, Le Belvédère, Tunis 1002, Tunisia; \\ soufiene.bouallegue@issig.rnu.tn (S.B.); joseph.haggege@enit.rnu.tn (J.H.) \\ 2 Automatic Control Group-ACG, Department of Automatic Control and Systems Engineering, \\ Engineering School of Bilbao, University of the Basque Country, 48012 Bilbao, Spain; \\ izaskun.garrido@ehu.es (I.G.); aitor.garrido@ehu.es (A.J.G.) \\ * Correspondence: kghefiri001@ikasle.ehu.eus; Tel.: +34-94-601-4443
}

Received: 30 January 2018; Accepted: 20 April 2018; Published: 24 April 2018

\begin{abstract}
Artificial intelligence technologies are widely investigated as a promising technique for tackling complex and ill-defined problems. In this context, artificial neural networks methodology has been considered as an effective tool to handle renewable energy systems. Thereby, the use of Tidal Stream Generator (TSG) systems aim to provide clean and reliable electrical power. However, the power captured from tidal currents is highly disturbed due to the swell effect and the periodicity of the tidal current phenomenon. In order to improve the quality of the generated power, this paper focuses on the power smoothing control. For this purpose, a novel Artificial Neural Network (ANN) is investigated and implemented to provide the proper rotational speed reference and the blade pitch angle. The ANN supervisor adequately switches the system in variable speed and power limitation modes. In order to recover the maximum power from the tides, a rotational speed control is applied to the rotor side converter following the Maximum Power Point Tracking (MPPT) generated from the ANN block. In case of strong tidal currents, a pitch angle control is set based on the ANN approach to keep the system operating within safe limits. Two study cases were performed to test the performance of the output power. Simulation results demonstrate that the implemented control strategies achieve a smoothed generated power in the case of swell disturbances.
\end{abstract}

Keywords: artificial intelligence; artificial neural networks control; back-to-back converter; data processing; Doubly Fed Induction Generator (DFIG); Maximum Power Point Tracking (MPPT); pitch regulation; power control; Tidal Stream Generator (TSG)

\section{Introduction}

Along with many emerging ambient intelligence techniques, artificial intelligence is a useful tool that has been applied successfully in a broad range of multi-discipline problems [1]. The artificial neural network is one of those techniques that can deal with nonlinear problems in diverse applications in signal processing [2], pattern recognition [3] and extended to renewable energy converters [4]. The development of applications based on sensor devices has been widely used in power generation plants [5]. The main role of the sensors has been the continuous monitoring of the plant parameters until the past few years. Furthermore, some concerns regarding the plant security or the need of efficiency improvement make sensors an essential component within the control system. These devices play an important role in the control scheme, which represents a necessary tool for parameter 
measuring and monitoring that are then used as control input variables to the feedback loop [6]. The global warming, the emission of greenhouse and harmful gases, and dangerous climate impacts (storm, flood, etc.) are the various global problems [7]. In addition to these problems, the cost of production and high energy consumption and depletion of fossil energy deposits lead many countries' policies to think seriously about their energy consumption [8]. In this context, several steps have been taken by several global constitutions to deal with economic and environmental issues. In this respect, the trends towards the study and exploitation of renewable energy have an inescapable necessity [9]. The world's oceans provide a significant energy, which has recently been widely exploited [10]. In fact, the potential for electrical energy production from marine tidal currents is interesting [11]. Thus, the tidal currents are being considered as alternative and competitive to fossil fuel in the production of electrical energy [12]. In order to achieve the sustainable development, many countries tend to focus on the huge potential of ocean energy. European Policy has successfully taken these forms of energy into their future projections. By 2050, power generated by the ocean energy sector could avoid the equivalent of $276 \mathrm{~m}$ tonnes of $\mathrm{CO}_{2}$ emissions annually [13]. The worldwide potential for wave and tidal of renewable energy is approximately $337 \mathrm{GW}$ [14].

The marine environment represents a source of energy, which could, theoretically, meet an important demand for power production; marine renewable energy converters are likely to play a significant part in a suite of technologies. This technology harvests the tidal current energy and extracts the kinetic energy from the flowing water. Environmental effects influence this form of energy. Thus, it is important that assessments of tidal current resources take into account more than the measured spring tidal currents [15]. In addition, it is not possible to consider the predictions based only on the nature of the natural flow [16]. Regarding the TSG systems, the swell effect is considered to be the most disturbing one for the tidal resource [17]. Tidal velocity can fluctuate due to the swell phenomenon and the induced changes in the tidal speed will lead to the disturbance of the TSG extractable power [18].

In the literature, several research works focused on the power output maximization of tidal stream converter systems [19]. The Maximum Power Point Tracking (MPPT) strategy is used to find the maximum power from tidal current and following the optimal regimes' characteristics [20]. The control of the generated power in a variable speed operation is ensured by the use of power electronic converters. The rotor side converter control is used to keep the rotational speed of the generator at its optimal value and to minimize the core losses [21], while the grid side converter control aims to maintain the voltage of the DC-link and control the reactive power [22]. In variable speed mode, a control strategy of a Marine Current Turbine (MCT) system with a non-pitched blade angle has been implemented in [23]. The Doubly Fed Induction Generator-based MCT has been used within a rotational speed control scheme. The simulation results demonstrate that the implemented control strategy provides good tracking speed performances. Nevertheless, the active power shows some tracking errors. In case of power limitation mode, the pitch angle control is used in order to optimize the extracted power and shedding mechanical load. As discussed in [24], a comparison of the pitch and stall angle controls has been investigated. The study suggests that the stall-regulated systems are not able to keep a constant power output in the case of strong tidal velocity. The pitch angle control contributes to more efficient results regarding the energy yields. Research works focused on the pitch angle control have been discussed in [25]. According to [26], two control strategies are proposed to ensure the power limitation at high tidal speed. The speed and torque control strategies have been implemented. The obtained results show that both approaches are capable of limiting the produced power to the rated value at steady-state. However, the torque control strategy is more efficient than speed control strategy due to the fact that the generated power is more directly controlled during dynamic stages. In order to overcome the drawbacks of a fix-pitched angle control, a novel multilayer neural networks based-complementary control is investigated in this paper. This control combines both aforementioned strategies to provide a suitable smoothing switching tool for an efficient and robust tidal energy converter against the swell effect phenomenon. 
This study aims to improve the performance and dynamic load assessment of the system under different operating conditions by adequately controlling the TSG transition under and above the tidal current speed threshold value. This novel complementary strategy focuses on the power smoothing control for the TSG system. The proposed control strategy is investigated using a multi-layer artificial neural networks strategy. This technique is used to provide the turbine rotational speed reference for which the maximum power is achieved and the pitch angular position in order to limit the generated power in the case of high tidal speeds. In power limitation mode, a comparative study of proportional and ANN-based controllers for the blade pitch angle of a Tidal Stream Turbine (TST) is discussed. ANN-based control aims to avoid frequent switching of the switch controller. In variable speed mode, a rotational speed control applied to the rotor side converter allows the system to follow the Maximum Power Point Tracking (MPPT) strategy. The principle of this control is to regulate the system so that, at each tidal speed, the turbine should track the rotational speed reference for which the maximum power is reached. The sensitivity of the proposed control strategies also have been evaluated in the case of turbulent tidal resources.

This paper is organized as follows; in Section 2, a background of the swell effect phenomenon and its influence on the power fluctuations is presented. After that, in Section 3, the TSG power plant is described and modeled. Section 4 implements the ANN-based control design of the MPPT-pitch angle strategy. Section 5 is devoted to the rotational speed control. In order to test the effectiveness of the proposed control approaches, two demonstrative study cases are presented and discussed in Section 6. Finally, concluding remarks are given in Section 7.

\section{Fluctuation Aspects of Tidal Power}

In marine energy, there are two types of power disturbances: on a large time-scale that is related to the neap and spring tides, i.e., tidal velocity changes each 6 or $12 \mathrm{~h}$ and on a short-time scale, where the period is on the order of a few seconds [27]. In this sense, the spread of the swell underwater represents the main disturbance for the tidal speed as well as the major cause of the short-time fluctuations in the TSG framework. For that reason, the swell effect should be considered in the modeling of the tidal speed. It should be noted that the generated power from the TSG would fluctuate severely when there are turbulences in the tidal current speed. Figure 1 shows a scheme of the swell characteristics.

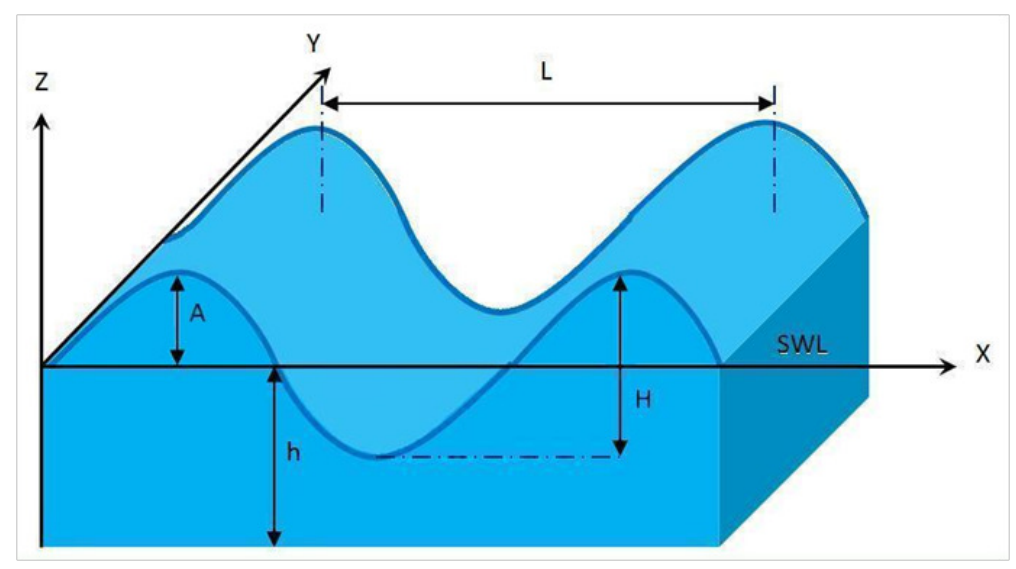

Figure 1. Swell characteristics.

The center line marking the mean water level is called Still Water Level (SWL). It is used to measure the water depth $h$ expressed in (m), which marks the distance from the seabed to the SWL. The portion of the wave profile with the highest elevation above the SWL is known as the wave crest and the part of the wave with the minimum depression is the wave trough. The distance between the wave trough and the wave crest is defined as the wave height $H$ in (m). Furthermore, the distance from the SWL up to the crest or down to the trough is the amplitude of the wave denoted 
as $A$ in (m). The wavelength $L$, expressed in (m), is the horizontal distance between the successive crests or successive troughs. The wavelength can also be defined as the horizontal distance between the successive points of equal amplitudes and phases.

The wavelength of a regular wave at any depth according to the linear theory can be defined as [28]:

$$
L=\frac{g T^{2}}{2 \pi} \tanh \left(\frac{2 \pi h}{L}\right),
$$

where $g$ is the gravity acceleration $9.81 \mathrm{~ms}^{-2}$ and $T$ is the swell period expressed in seconds $(s)$.

The swell effects on a tidal current velocity can be modeled using first order Stokes model [29]. The horizontal tidal speed (which is represented in the $x$-axis direction of Figure 1) can be determined using the following equation [30]:

$$
V_{x}(t)=\frac{\pi \mathrm{H}}{T} \frac{\cosh \left(2 \pi\left(\frac{z+h}{L}\right)\right)}{\sinh \left(2 \pi \frac{h}{L}\right)} \cos 2 \pi\left(\frac{t}{T}-\frac{x}{L}\right),
$$

where $x$ and $z$ are the horizontal and vertical point for the calculation.

According to Equation (2), only the sinusoidal swell is considered. However, from a real point of view, more than one frequency component should be taken into account to model the swell effects. Based on the JONSWAP spectrum and wave theories [31], each swell frequency component is determined. Assuming that $V_{\text {rated }}$ is the predicted rated tidal speed, which can be considered as a constant during a period less than one hour, the following equation is used to calculate the tidal velocity taking into account the swell effects [29]:

$$
V(t)=V_{\text {rated }}+\sum_{i} \frac{2 \pi a_{i}}{T_{i}} \frac{\cosh \left(2 \pi\left(\frac{z+h}{L_{i}}\right)\right)}{\sinh \left(2 \pi \frac{h}{L_{i}}\right)} \cos 2 \pi\left(\frac{t}{T_{i}}-\frac{x}{L_{i}}+\varphi_{i}\right),
$$

where $\varphi_{i}$ is the initial phase angle of each frequency component that is given randomly and $a_{i}$ represents the amplitude of each frequency component.

Figure 2 shows the tidal current speed profile under the swell effect during $5 \mathrm{~min}$. The rated tidal speed is considered at $3 \mathrm{~m} / \mathrm{s}$. It can be noted that the swell effect phenomenon can provoke large oscillations in the tidal speed for a given sea state. Consequently, these fluctuations induce high disturbances at the TSG extracted power.

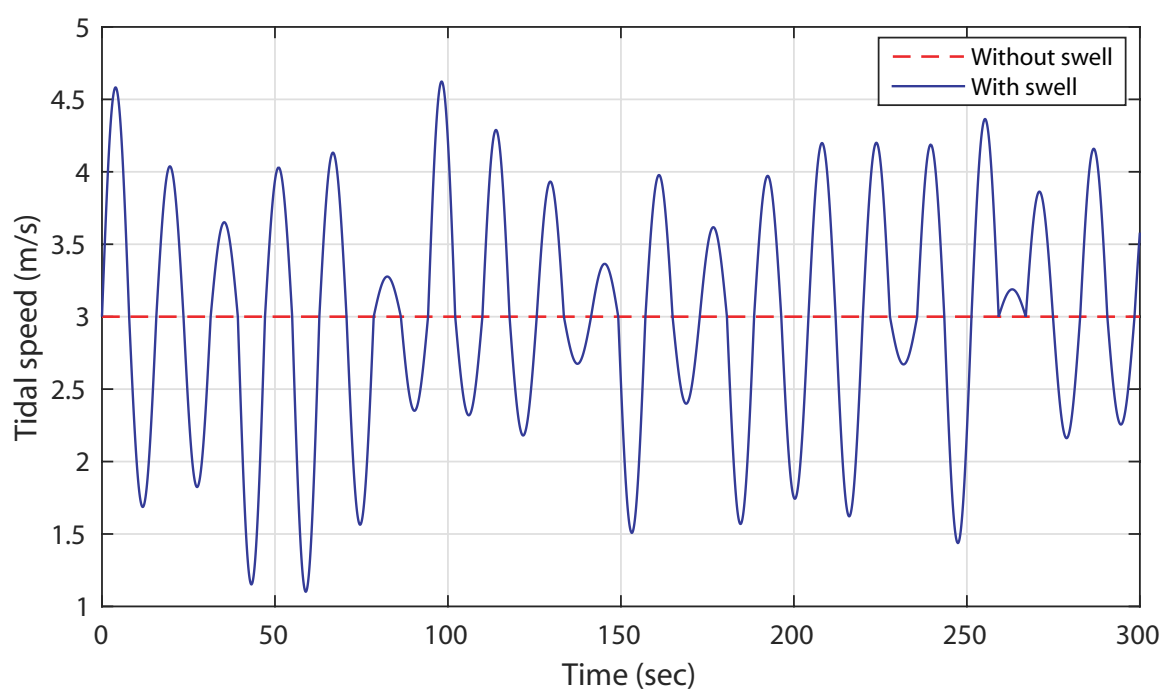

Figure 2. Tidal current speed profile with swell effect phenomenon. 


\section{Control Objectives and Modeling of the Tidal Stream Generator}

\subsection{Control Problem Statement}

The TSG system consists of a Tidal Stream Turbine (TST) coupled to a Doubly Fed Induction Generator (DFIG) connected to the grid through the Back-to-Back power converter as shown in Figure 3. The turbine converts the kinetic energy from the tidal current speed to the rotation of the rotor shaft. The DFIG is coupled to the rotor shaft through the drive-train, which is adapted to the grid through the back-to-back power converters.

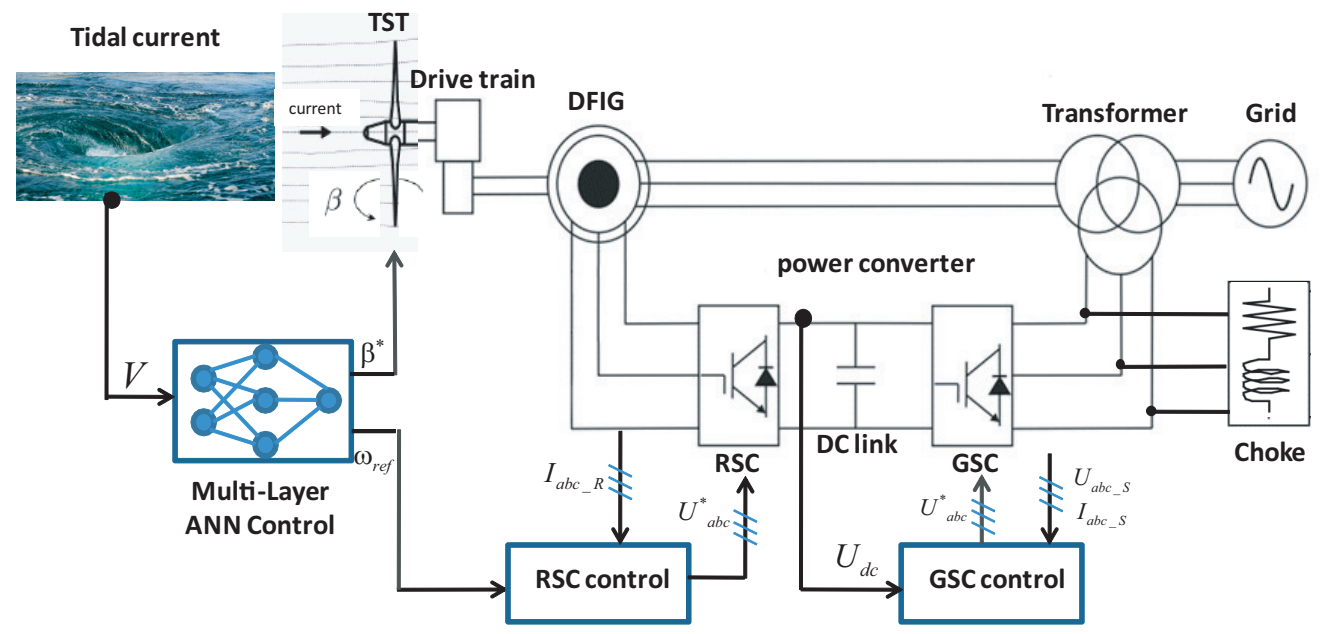

Figure 3. General scheme of a DFIG-based TST system and control description.

The control strategy describes how the tidal turbine is designed to approach the steady state of the ideal power curve. This amounts to adjusting the values of power and rotor speed at steady-state for each tidal speed in the range of the turbine operation. The control system may vary from one region of operation to another.

The ANN block provides two reference trajectories to the system: the suitable rotational speed reference following the MPPT strategy to maximize the extracted power; and the adequate angle of attack of the turbine blades to limit the power captured in the case of high tidal current speed. The control of the electrical part of the system is devoted to the DFIG focusing on the active and reactive powers' control. This control approach is realized by the power electronics converters such as the Rotor Side Converter (RSC) and the Grid Side Converter (GSC). The RSC aims to maintain the rotational speed of the generator at an optimal value and minimizes the core losses while the GSC is used to maintain the voltage of the DC-link and controls the output reactive power.

\subsection{Tidal Turbine Model}

The hydrodynamic phenomenon of the tidal turbine is described by the following expression [32,33]:

$$
P_{t}=\frac{1}{2} C_{p}(\lambda, \beta) \rho \pi R^{2} V^{3}
$$

where $P_{t}$ represents the power captured from the tides in $(\mathrm{W}), R$ is the radius of the blades given in $(\mathrm{m}), \rho$ is the fluid density in $\left(\mathrm{kg} / \mathrm{m}^{3}\right)$ and $V$ is the current speed in $(\mathrm{m})$.

The tidal turbine does not use the total harnessed power from the tidal velocity due to Betz limit [34]. In addition, $C_{p}$ describes the power coefficient that depends on the pitch angle $\beta$ in (deg) and the tip-speed ratio $\lambda$, expressed as follows [35]:

$$
\lambda=\frac{\omega_{t} R}{V}
$$


where $\omega_{t}$ is the rotational speed of the rotor given in $(\mathrm{rad} / \mathrm{s})$.

The hydrodynamic turbine torque, expressed in $(\mathrm{Nm})$, is governed by the following equation:

$$
T_{t s t}=\frac{P_{t}}{\omega_{t}}
$$

\subsection{Shaft Model}

The tidal turbine is coupled to the DFIG via a drive train shaft. The two-mass model is used to describe the rotor shaft dynamics, which characterize the mechanical behavior of the turbine and the generator. The dynamic system is given as follows [36]:

$$
\begin{gathered}
T_{t s t}-T_{t}=2 H_{t} \frac{d \omega_{t}}{d t}, \\
T_{t}=D_{s h}\left(\omega_{t}-\omega_{g}\right)+K_{s h} \int\left(\omega_{t}-\omega_{g}\right) d t \\
T_{t}-T_{e m}=2 H_{g} \frac{d \omega_{g}}{d t},
\end{gathered}
$$

where $T_{t}$ is the torque produced by the generator shaft in (Nm), $T_{e m}$ is the electromagnetic torque in $(\mathrm{Nm})$ and $\omega_{g}$ is the rotational speed of the generator in $(\mathrm{rad} / \mathrm{s}) . K_{s h}$ is the stiffness coefficient in $(\mathrm{Nm} / \mathrm{rad}), D_{s h}$ is the damping coefficient in $(\mathrm{Nms} / \mathrm{rad}), H_{t}$ and $H_{g}$ are the inertia constants expressed in seconds for the tidal turbine and generator, respectively [37].

\subsection{Generator Model}

The variable speed operation of the DFIG-based TST has many advantages over other generator concepts. Their ability to generate power over a wide speed range in both sub- and super-synchronous modes makes them more attractive $[19,38,39]$. The dynamic model of the DFIG is defined in the synchronous rotating frame $(d-q)$ using Park's transformation [40]. The expressions of the stator voltages and flux, given in $(\mathrm{V})$ and in $(\mathrm{Wb})$ respectively, are defined as follows [41]:

$$
\begin{gathered}
\left\{\begin{array}{l}
U_{s d}=R_{s} I_{s d}+\frac{d \varphi_{s d}}{d t}-\omega_{s} \varphi_{s q}, \\
U_{s q}=R_{s} I_{s q}+\frac{d \varphi_{s q}}{d t}-\omega_{s} \varphi_{s d}
\end{array}\right. \\
\left\{\begin{array}{l}
\varphi_{s d}=L_{s} I_{s d}+L_{m} I_{r d}, \\
\varphi_{s q}=L_{s} I_{s q}+L_{m} I_{r q} .
\end{array}\right.
\end{gathered}
$$

The rotor voltages and flux are defined by the following equations [42]:

$$
\begin{gathered}
\left\{\begin{array}{l}
U_{r d}=R_{r} I_{r d}+\frac{d \varphi_{r d}}{d t}-\omega_{r} \varphi_{r q}, \\
U_{r q}=R_{r} I_{r q}+\frac{d \varphi_{r q}}{d t}-\omega_{r} \varphi_{r d},
\end{array}\right. \\
\left\{\begin{array}{l}
\varphi_{r d}=L_{r} I_{r d}+L_{m} I_{s d}, \\
\varphi_{r q}=L_{r} I_{r q}+L_{m} I_{s q} .
\end{array}\right.
\end{gathered}
$$

The electromagnetic torque of the generator is expressed in the $d-q$ frame by Equation (14):

$$
T_{e m}=\frac{3}{2} p L_{m}\left(I_{s q} I_{r d}-I_{s d} I_{r q}\right),
$$

where $I_{s d}, I_{s q}$ are the stator currents defined in $d$-q synchronous frame in (A), $I_{r d}, I_{r q}$ are the rotor currents defined in $d-q$ axis in (A), $R_{s}$ and $R_{r}$ are the stator and rotor resistances in $(\Omega), \omega_{s}$ and $\omega_{r}$ are the stator and rotor pulsations in $(\mathrm{rad} / \mathrm{s}), L_{s}$ and $L_{r}$ are the stator and rotor inductances in $(\mathrm{H}), L_{m}$ is the magnetizing inductance in $(\mathrm{H})$ and $p$ is the pole pair number. 


\subsection{Power Converters Model}

The use of the power electronics converter is the key to connect the system to the grid via the DC-link capacitor [40-44]. The AC-DC-AC converter is formed by the GSC connected to the grid and the RSC connected to the DFIG as depicted in Figure 3. The GSC is intended to keep the DC-link voltage constant regardless of the magnitude and direction of the rotor power using a vector control strategy [45]. However, the role of RSC is improving the operation of the DFIG providing maximum power production using a vector control strategy [46].

The equations of the active and reactive powers of the system, expressed in (W) and (VAR) respectively, are given as follows [47]:

$$
\begin{aligned}
P_{g} & =\frac{3}{2}\left(U_{d g} I_{d g}-U_{q g} I_{q g}\right), \\
Q_{g} & =\frac{3}{2}\left(U_{q g} I_{d g}-U_{d g} I_{q g}\right),
\end{aligned}
$$

where $U_{d g}, U_{q g}$ in $(\mathrm{V})$ and $I_{d g}, I_{q g}$ in (A) are the grid voltages and currents defined in the $d$ - $q$ reference frame, respectively.

In order to achieve the voltage oriented control, the $d$-axis of the synchronous frame and the grid voltage vector are aligned, i.e., $U_{d g}=U_{g}$ and $U_{q g}=0$. Hence, the equations of the active and reactive powers can be rewritten as follows [47]:

$$
\begin{gathered}
P_{g}=\frac{3}{2} U_{g} I_{d g}, \\
Q_{g}=-\frac{3}{2} U_{g} I_{q g} .
\end{gathered}
$$

The expression between the power stored in the DC-link and the power transferred to the grid is defined by Equation (19) [48]:

$$
P_{g}=\frac{3}{2} U_{g} I_{d g}=U_{d c} I_{d c}
$$

where $U_{d c}$ in $(\mathrm{V})$ is the DC bus voltage and $I_{d c}$ in $(\mathrm{A})$ is the current accross the DC-link.

\section{Artificial Neural Networks Based-Planning Control Trajectories}

An Artificial Neural Network can efficiently approximate and interpolate multivariate data that might otherwise require huge databases [49]. Such a technique is well accepted for nonlinear statistical fitting applications $[50,51]$. The nonlinearity aspect of the tidal stream turbine along with the integration of the DFIG and the connection to the grid through the back-to-back power converter makes this system more complex. In this context, a multi-layer ANN is proposed as a promising solution to deal with the nonlinearity of the system from tides to the grid. The implemented ANN block aims to provide two reference trajectories. On one hand, the turbine rotational speed reference for which the maximum power is achieved. On the other hand, the pitch angular position in order to limit the generated power in the case of high tidal speeds.

\subsection{Multi-Layer ANN Control Design}

In a TSG system, the turbine exhibits an optimal performance at a specific rotational speed. For each tidal speed, there is a certain rotational speed at which the harnessed power reaches its maximum value [52]. Figure 4 shows the variation of the generated power versus the rotational speed for different tidal currents. 


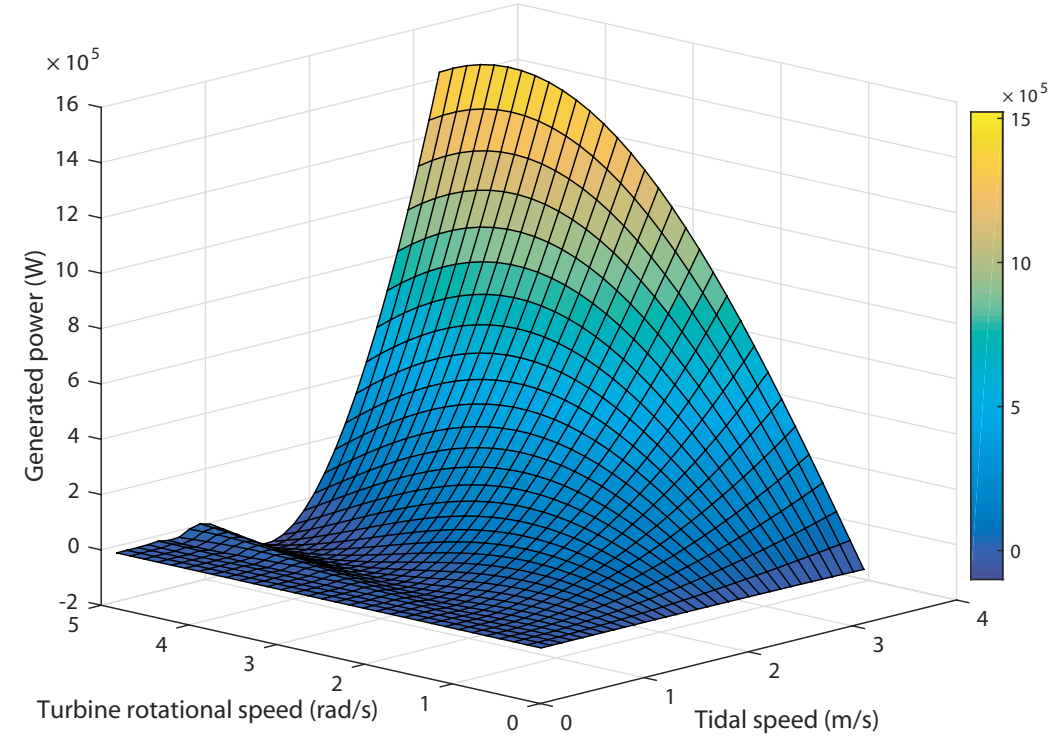

Figure 4. Generated power versus rotational speed for different tidal speeds.

All these maxima define what is known in the literature as the Optimal Regimes Characteristic (ORC) [53] . According to the turbine under study, the maximum power coefficient is $C_{p \max }=0.44$ corresponding to the optimal tip-speed ratio $\lambda_{\text {opt }}=6.34$. The maximum extractable power is $P_{n}=1.5 \mathrm{MW}$ at the rated tidal speed $V_{n}=3.2 \mathrm{~m} / \mathrm{s}$. In this variable speed mode, the generated power varies as the tidal current speeds are changing for certain rotational speed for a fixed pitch angle assumed null. From this simulation, it can be noted that, for each specific tidal speed input, the tidal turbine can harness the maximum power for a certain rotational speed.

In the case of high tidal speeds and strong waves, the pitch angle control is used to limit the harnessed power by adequately rotating the blades at the suitable angular position. As depicted in Figure 5, the generated power varies with the rotational speed for different values of the pitch angle at the rated tidal speed $V_{n}$. The maximum power is reached at $\beta=0^{\circ}$. It should be noted that as the pitch angle augments the generated output power decreases for a specific rotational speed. This study shows the effect of the pitch angle control to keep the system operating within safe specified limits.

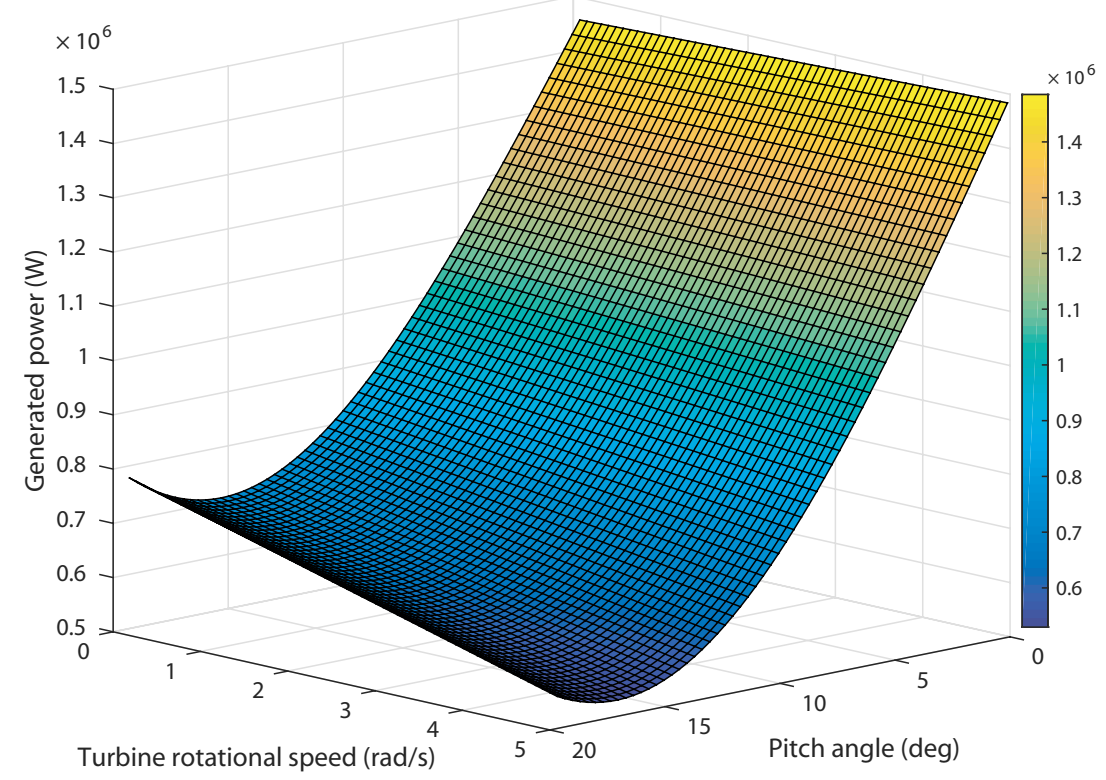

Figure 5. Generated power versus rotational speed for different pitch angles at rated tidal speed. 
Based on the characteristic curves of the studied TST, the feed-forward ANN is designed to generate the MPPT reference to the RSC's controller and the desired pitch angle to the pitch actuator. The architecture of a multi-layer ANN, in the general case, consists of the input, hidden and output layers as shown in Figure 6. The information flowing from the input to the output neurons is assured by the neurons of the hidden layers with the appropriate weights and activation functions.

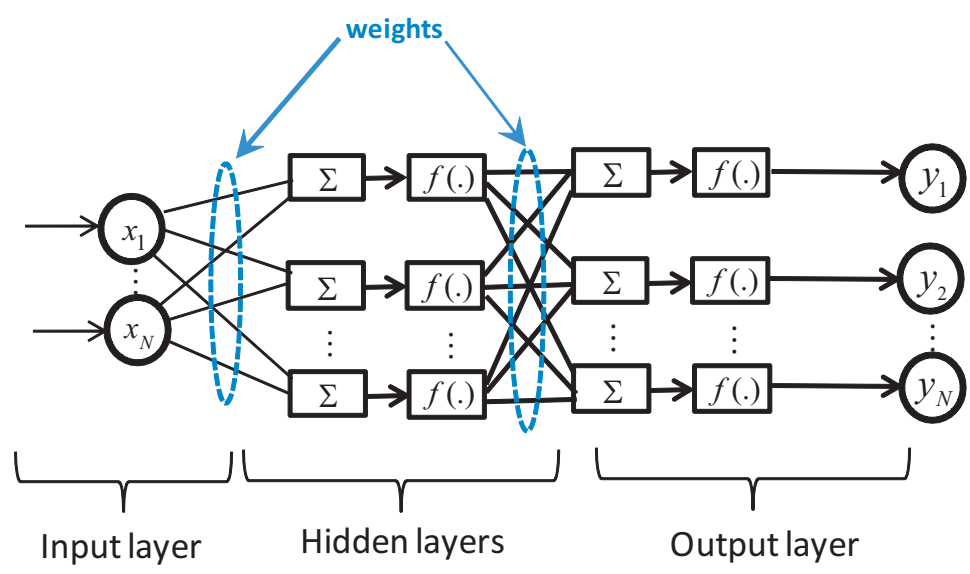

Figure 6. Layout of a multilayer ANN.

In order to design the ANN block, we have to set the appropriate input and output data of the TST system. The ANN block is trained in the way that it can generate the suitable rotational speed reference following the MPPT strategy and fixing the pitch angle null. When the tidal turbine reaches the maximum power, the system should switch to assure the required pitch angle for each input data to prevent the overload of the turbine. The implemented feed-forward network is composed of one input layer with one neuron, which represents the tidal speed variation and one output layer with two neurons. Due to the complexity of the multi-physic system which fully integrates the hydrodynamic loads, turbine, induction generator and the back-to-back converter models, the authors opted for using the trial-and-error rule based on forward approach procedure [54]. This starts with undersized number of hidden neurons and adds the number of neurons. After that, train and test the neural network. Then, the number of hidden neurons is increased and the above procedure repeated until the training and testing results are improved. This method is based on a statistical analysis by satisfying as performance criteria the best mean squared error achieved. During simulation, several values of neurons of the hidden layer were tested in order to obtain the smallest Mean Squared Error (MSE) to achieve the best validation performance. The activation function used in the hidden layer is with the hyperbolic tangent type, whereas that corresponding to the output neuron was chosen linear.

After adjusting the structure of the neuro-controllers, the Levenberg-Marquardt (LM) algorithm is adopted as a learning method for training the ANN [55]. The LM algorithm is a variation of Newton's method that was designed for minimizing functions that are sums of squares of other nonlinear functions [56]. The algorithm should adjust the network parameters in order to minimize the performance index as follows [57]:

$$
\Delta X=\left[\nabla^{2} F(X)\right]^{-1} \nabla F(X),
$$

where $\nabla^{2} F(X)$ is the Hessian matrix and $\nabla F(X)$ is the gradient.

Considering $F(X)$ as the performance index, which is defined as follows:

$$
F(X)=\sum_{i=1}^{N} e_{i}^{2}(X)=e^{T}(X) e(X) .
$$


Its gradient may be rewritten as:

$$
\nabla F(X)=2 J^{T}(X) e(X),
$$

where $J(X)$ is the Jacobian matrix.

The LM algorithm implementation requires the calculation of the Jacobian matrix, with a size proportional to the number of training patterns as follows [58]:

$$
J(X)=\left(\begin{array}{cccc}
\frac{\partial e_{1}(X)}{\partial X_{1}} & \frac{\partial e_{1}(X)}{\partial X_{2}} & \ldots & \frac{\partial e_{1}(X)}{\partial X_{n}} \\
\frac{\partial e_{2}(X)}{\partial X_{1}} & \frac{\partial e_{2}(X)}{\partial X_{2}} & \ldots & \frac{\partial e_{2}(X)}{\partial X_{n}} \\
\vdots & \vdots & \ddots & \vdots \\
\frac{\partial e_{N}(X)}{\partial X_{1}} & \frac{\partial e_{N}(X)}{\partial X_{2}} & \ldots & \frac{\partial e_{N}(X)}{\partial X_{n}}
\end{array}\right)
$$

Then, the Hessian matrix can be expressed in the following form:

$$
\nabla^{2} F(X)=2 J^{T}(X) J(X)+2 S(X)
$$

where:

$$
S(X)=\sum_{i=1}^{N} e_{i}(X) \nabla^{2} e_{i}(X)
$$

In order to select the adequate number of neurons of the hidden layer, an empirical comparative study is performed through different tests. The evaluation of the performance of the used LM algorithm was established taking into account the number of the epochs and the mean squared error found. Table A1 of Appendix A shows the performance of the training process for different numbers of neurons in the hidden layer.

Training tests show that, by increasing the number of neurons in the hidden layer from 2 to 11, the LM algorithm reaches a lower optimization stopping criteria for a higher number of epochs. The MSE increases for $h_{i}$ higher than 10, which indicates that the network can be overtrained using those patterns.

\subsection{Training Performance of ANN-Based Controller}

The best validation performance is $38,614 \cdot 10^{-5}$ at 1000 epochs which corresponds to $h_{i}=10$. Figure 7 indicates the iteration at which the validation performance reached a minimum. This feature shows that the training data indicates a good fit.

Figure 8 shows the response of the MPPT based-ANN control strategy by changing $h_{i}$ for the tidal speed ranging from 0 to $5 \mathrm{~m} / \mathrm{s}$. When the tidal speed varies over the range $[0,3.2 \mathrm{~m} / \mathrm{s}]$, the rotational speed reference is adjusted to track the optimal reference for which the power coefficient is at its maximum value $\left(C_{p \max }=0.44\right)$. Once the tidal speed reaches the tolerable value, which is $3.2 \mathrm{~m} / \mathrm{s}$, the speed reference should maintain the nominal value $\omega_{n}=2.53 \mathrm{rad} / \mathrm{s}$. Note that all the generated references ensure the MPPT in the variable speed operation mode, whereas, in power limitation mode, the trajectory of the rotational speed, which corresponds to $h_{i}=10$, is the most stable response and is able to keep $\omega_{\text {ref }}$ around $\omega_{n}$.

Figure 9 shows the response of the pitch angle control based-ANN by varying the tidal speed from 0 to $5 \mathrm{~m} / \mathrm{s}$. When the tidal speed varies over the range $[0,3.2 \mathrm{~m} / \mathrm{s}]$, the pitch angle response is null for all the tested $h_{i}$. As the tidal speed reaches $3.2 \mathrm{~m} / \mathrm{s}$, the value of the pitch angle increases accordingly with the variation of the input. 


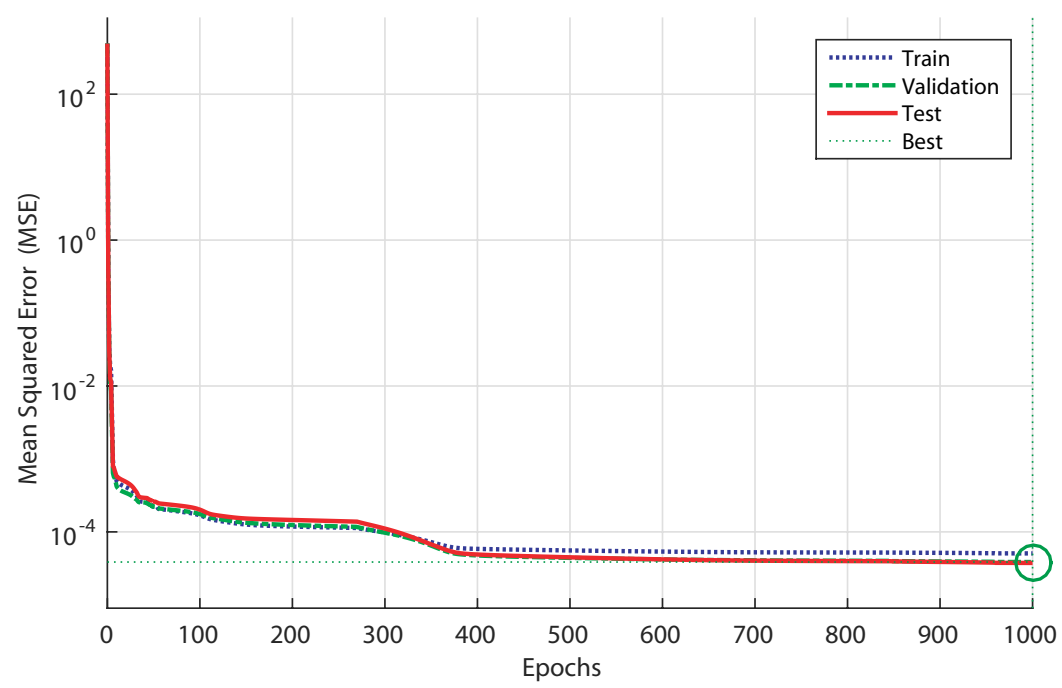

Figure 7. Performances of the multi-layer ANN training.

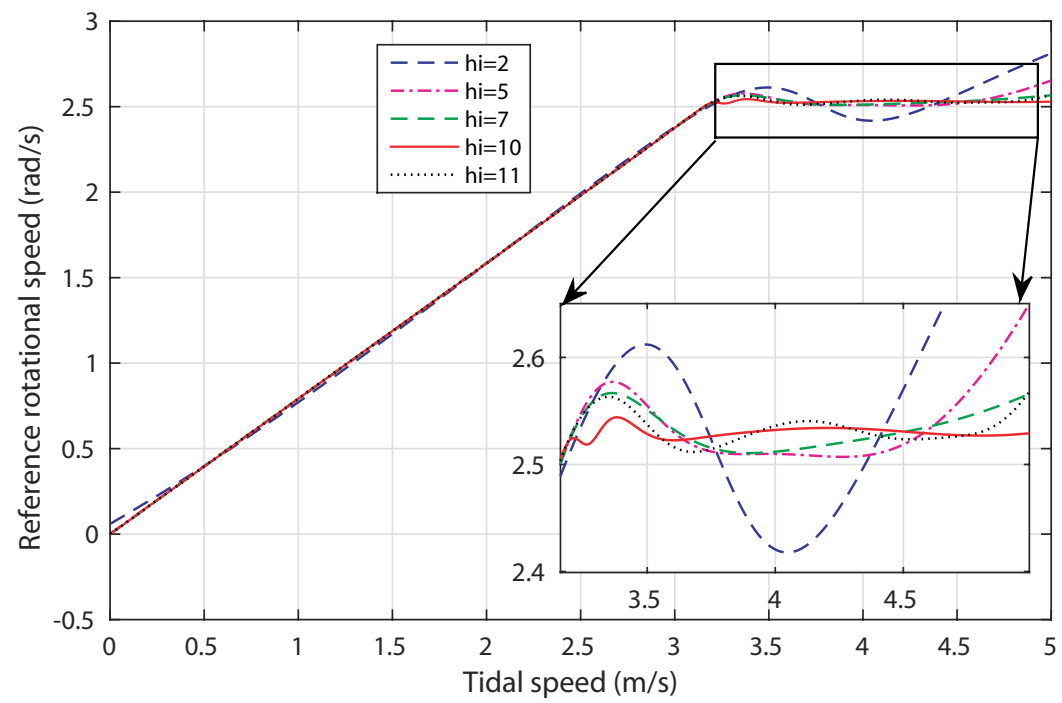

Figure 8. Response of the ANN-based MPPT control.

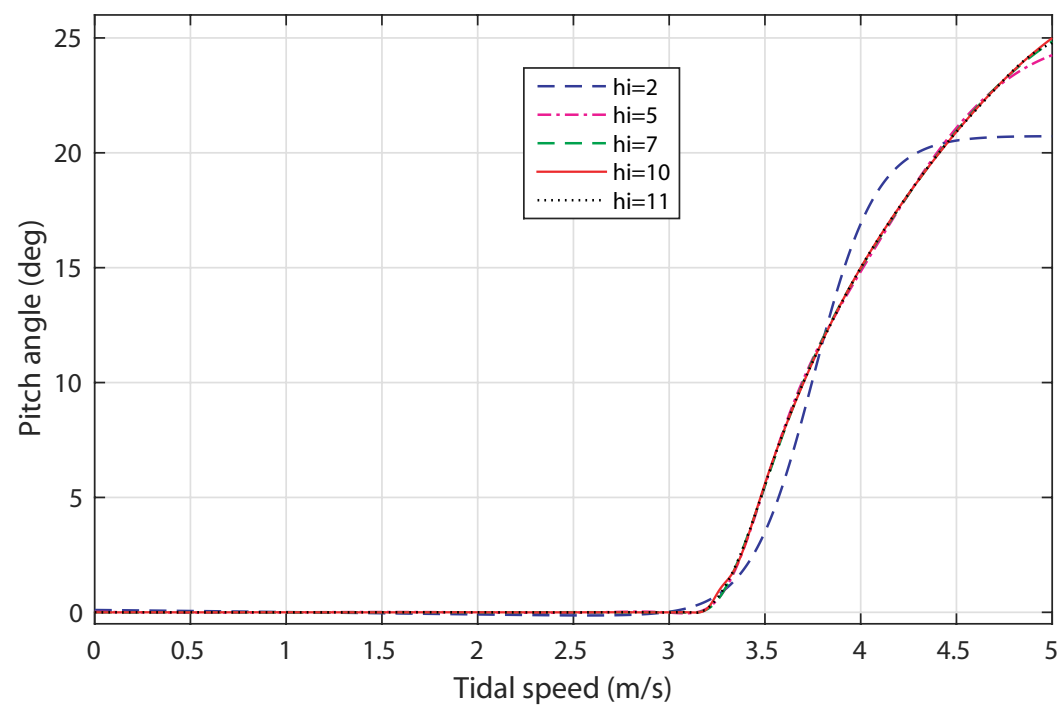

Figure 9. Response of the ANN-based pitch angle control. 


\section{Rotational Speed Control of TSG System}

\subsection{Rotor Side Converter Control}

For the RSC, the stator flux control strategy is applied as depicted in Figure 10. The needed variables in this control scheme are the stator and rotor currents, the stator voltage and the rotor speed. The control design structure consists of one outer loop for the rotational speed and two inner loops for currents' regulation.

The reference speed $\omega_{\text {ref }}$ is generated from the implemented ANN block as discussed previously in Section 4 according to the MPPT approach. The ANN output is used for the speed control loop, which defines a reference for the $q$-axis rotor current $i_{q r}^{*}$. The $d$-axis current reference $i_{d r}^{*}$ is set to zero, whereas the inner current control loop determines the $d-q$ rotor voltage reference. The expressions that link between the rotor voltages in (V) and currents in (A) are defined by Equation (26) as given in [40]:

$$
\left\{\begin{array}{l}
U_{d r}=R_{r} i_{d r}+\sigma L_{r} \frac{d i_{d r}}{d t}, \\
U_{q r}=R_{r} i_{q r}+\sigma L_{r} \frac{d i_{q} r}{d t},
\end{array}\right.
$$

where $\sigma$ is the leakage factor.

Furthermore, decoupling terms are added to the equations of $U_{d r}^{*}$ and $U_{q r}^{*}$ that will improve the transient response of the system [59]. Thus, the rotor voltage references are given as follows:

$$
\left\{\begin{array}{l}
U_{d r}^{*}=-\omega_{s l i p} \sigma L_{r} i_{q r}+\left(K_{P i} e_{d}+K_{I i} \int e_{d} d t\right), \\
U_{q r}^{*}=\omega_{s l i p}\left(L_{m} i_{m}+\sigma L_{r} i_{d r}\right)+\left(K_{P i} e_{d}+K_{I i} \int e_{d} d t\right),
\end{array}\right.
$$

where $\omega_{\text {slip }}$ is the slip angular frequency in ( $\left.\mathrm{rad} / \mathrm{s}\right)$ and $i_{m}$ is the stator magnetizing current assumed as constant. $K_{P i}$ and $K_{I i}$ denote the gains of PI controllers.

The PI controllers design is performed using the Ziegler-Nichols method [60]. Then, using the robust response time algorithm, further refinement on the initial value of the PI gains were applied [61]. The rotor voltage references are transformed to the three-phase $a b c$ stationary frame to be applied to the RSC via the Pulse Width Modulation (PWM) block.

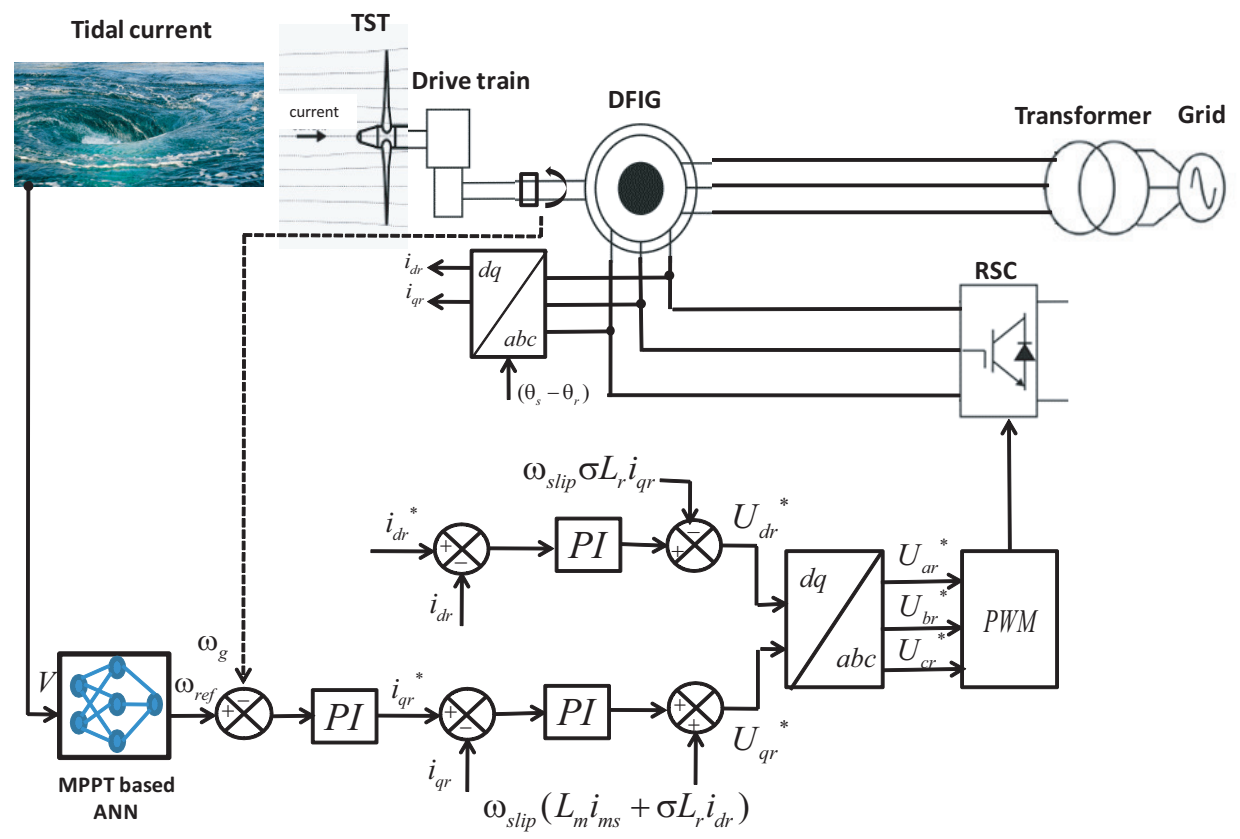

Figure 10. Stator flux oriented control strategy for the RSC. 


\subsection{Grid Side Converter Control}

The GSC is controlled by the voltage oriented control scheme as depicted in Figure 11. The control strategy consists of two series of PI controllers within a cascade configuration. The implemented scheme controls the DC-link voltage $U_{d c}$ and the reactive power $Q_{g}$. The Phase Locked Loop (PLL) block is used to recover the phase of the input signal, which is $\theta_{g}$. The direct and quadrature components of the currents in (A) and voltages in (V) are obtained using Park's transformation.

The grid voltages in $(\mathrm{V})$ are defined in the $d-q$ reference frame as follows:

$$
\left\{\begin{array}{l}
U_{g d}=i_{d s} R_{g}+L_{g} \frac{d i_{d s}}{d t}-\omega_{s} L_{g} i_{q s}+U_{g d 1}, \\
U_{g q}=i_{q s} R_{g}+L_{g} \frac{d i_{q s}}{d t}-\omega_{s} L_{g} i_{d s}+U_{g q 1},
\end{array}\right.
$$

where $R_{g}$ in $(\Omega)$ and $L_{g}$ in $(\mathrm{H})$ are the grid coupling resistance and inductance respectively, $U_{g d 1}$ and $U_{g q 1}$ in $(\mathrm{V})$ are the two phase converter terminal voltages.

According to Equations (17) and (18), the active and reactive powers are controlled via the $d$-axis and $q$-axis current, respectively. The current control loops are identical and generate the grid voltage references $U_{d s}^{*}$ and $U_{q s}^{*}$ defined by Equation (29). Then, compensator terms and feed-forward voltages are added to the control signals in order to enhance the transient response of the system [62]:

$$
\left\{\begin{array}{l}
U_{g d}^{*}=U_{g d}+\Omega_{g} L_{g} i_{q}-\left(K_{P i} e_{d}+K_{I i} \int e_{d} d t\right), \\
U_{g q}^{*}=U_{g q}-\Omega_{g} L_{g} i_{d}-\left(K_{P i} e_{q}+K_{I i} \int e_{q} d t\right) .
\end{array}\right.
$$

The outer voltage loop is designed to control the DC voltage $U_{d c}$ and keep it constant. The two inner current loops are intended to regulate the $d$-axis and $q$-axis currents $i_{d s}$ and $i_{q s}$. The quadrature current component $i_{q s}$ is used to regulate the reactive power. During the normal operation, the converter will transfer all the generated TST active power to the grid. Thus, the $q$-axis current reference is assuming zero. Similarly to the RSC case, the design of the PI controllers is carried out using the experimental Ziegler-Nichols method. Finally, the reference voltages transformed to the three phase $a b c$ frame are then used to generate all PWM signals for the GSC block.

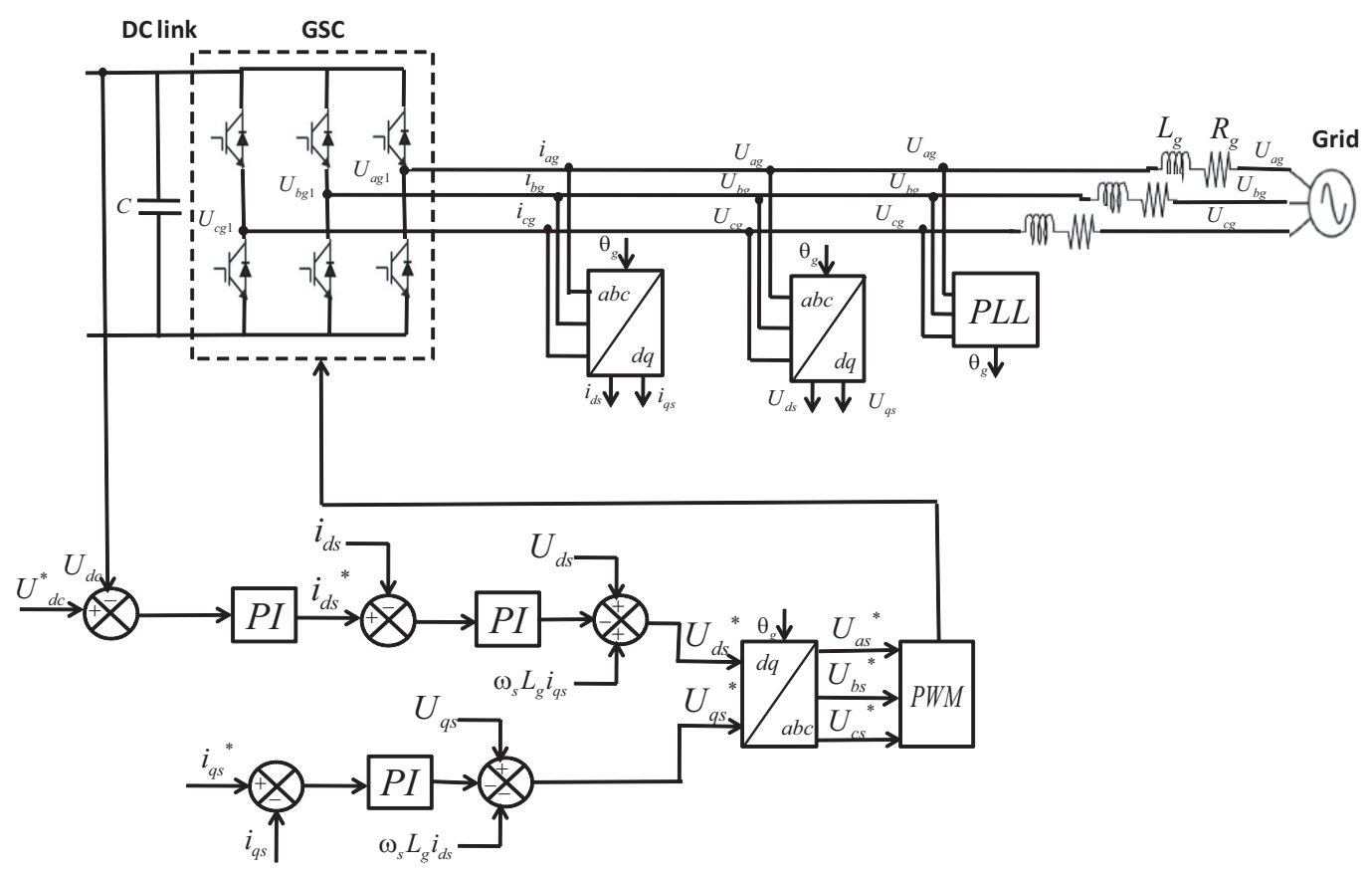

Figure 11. Voltage oriented control strategy for the GSC. 


\section{Validation Tests and Discussion}

In this section, two study cases are presented to investigate the effectivness of the proposed control strategies in order to improve the generated power output and to test the robustness of the ANN control against swell effect disturbances. Simulations have been carried out to validate the proposed ANN-based control using the model described in Section 3 and implemented as shown in Figure 12. For all performed simulations, the used model parameters are listed in Table A2 of Appendix A.

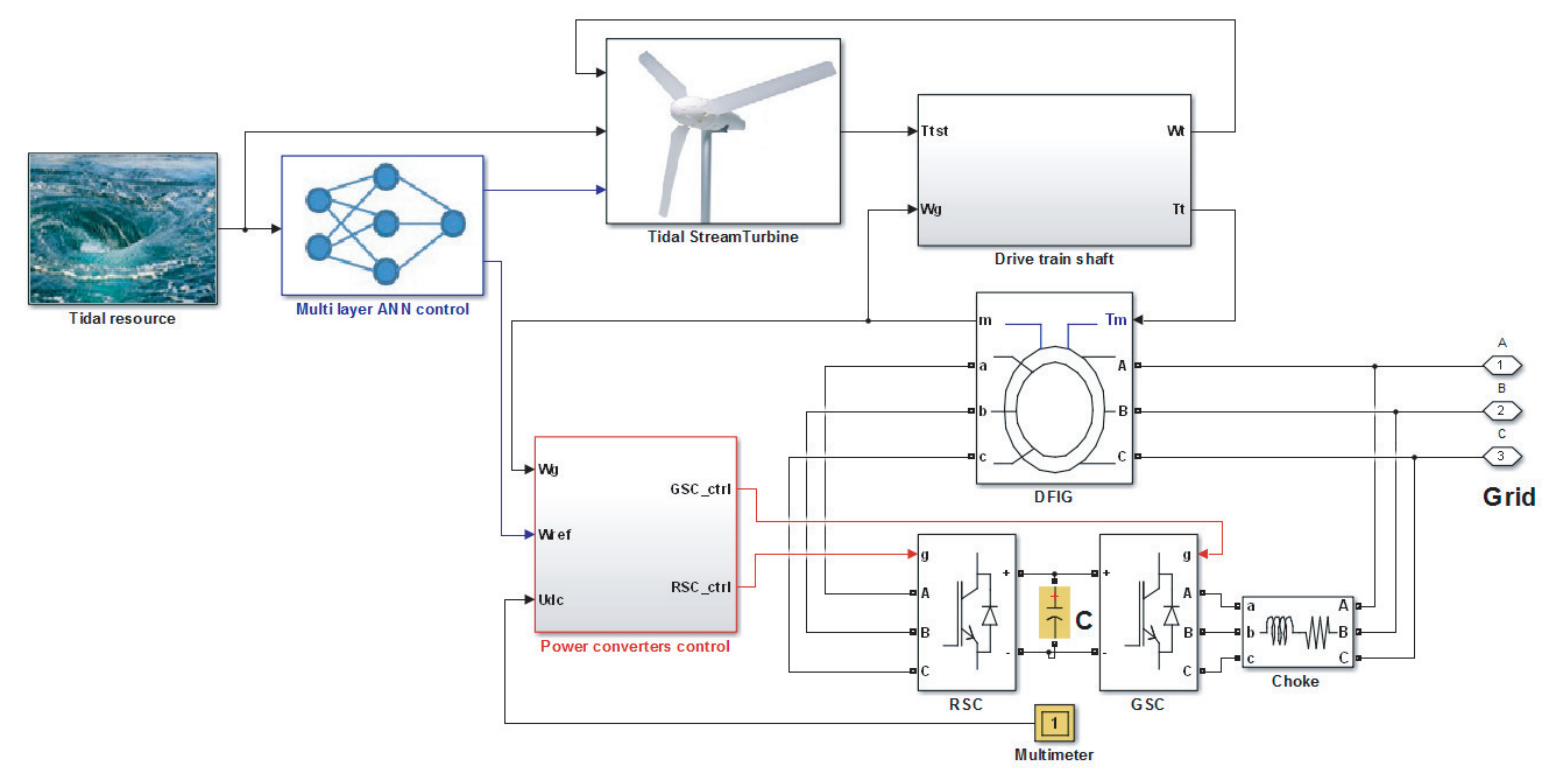

Figure 12. Numerical implementation of the TSG model.

\subsection{Comparative Study between the Switching and ANN-Based Controls}

In order to test the effectiveness of the proposed control strategies, this study case is set to compare the ANN-based control scheme with a switching control investigated in previous research work [32] for the same TSG system.

The scenario considered for the tidal current speed takes the shape of a semidiurnal spring and neap tides. The tidal speed input is illustrated in Figure 13. It can be seen that the maximum pic of the spring and neap tides achieve the value $3.6 \mathrm{~m} / \mathrm{s}$ and $3.2 \mathrm{~m} / \mathrm{s}$, respectively.

Figure 14 illustrates the comparison between the responses of the power coefficient and the pitch angle with a conventional switch controller and ANN-based strategy. It is obvious that ANN control successfully adjusts the blade pitch angle as well as the power coefficient with the change of the tidal speed. In contrast, the switching control does not adapt well to all input changes. The power coefficient is maintained at its maximum value 0.438 in variable speed mode and decreases at high tidal velocity. Consequently, the angular position of the turbine blades is kept null in the variable speed mode and increases in the power limitation mode. It is noted that the generated signals are time varying, which makes the proportional feedback inefficient. By using a multi-layer ANN-based controller in the power limitation mode, the tracking performances of the adequate pitch angle of the blades at each tidal speed are clearly improved.

The rotor speed increases according to the flow speed input and it is kept constant below the threshold value as depicted in Figure 15. On one hand, when the tidal speed is below the rated value $(3.2 \mathrm{~m} / \mathrm{s})$, both control approaches lead to a good tracking of the rotational speed. On the other hand, when tidal current is higher than the rated value, the ANN-based controller shows an improved tracking of the rotational speed.

The resulting generated power variation is shown in Figure 16. The tidal turbine is able to maximize the generated power below nominal tidal velocity and then is kept at the nominal power. 
By using the proposed ANN control, it is obvious that the peak of change during the transition between two modes is eliminated. This leads to a power generation improvement.

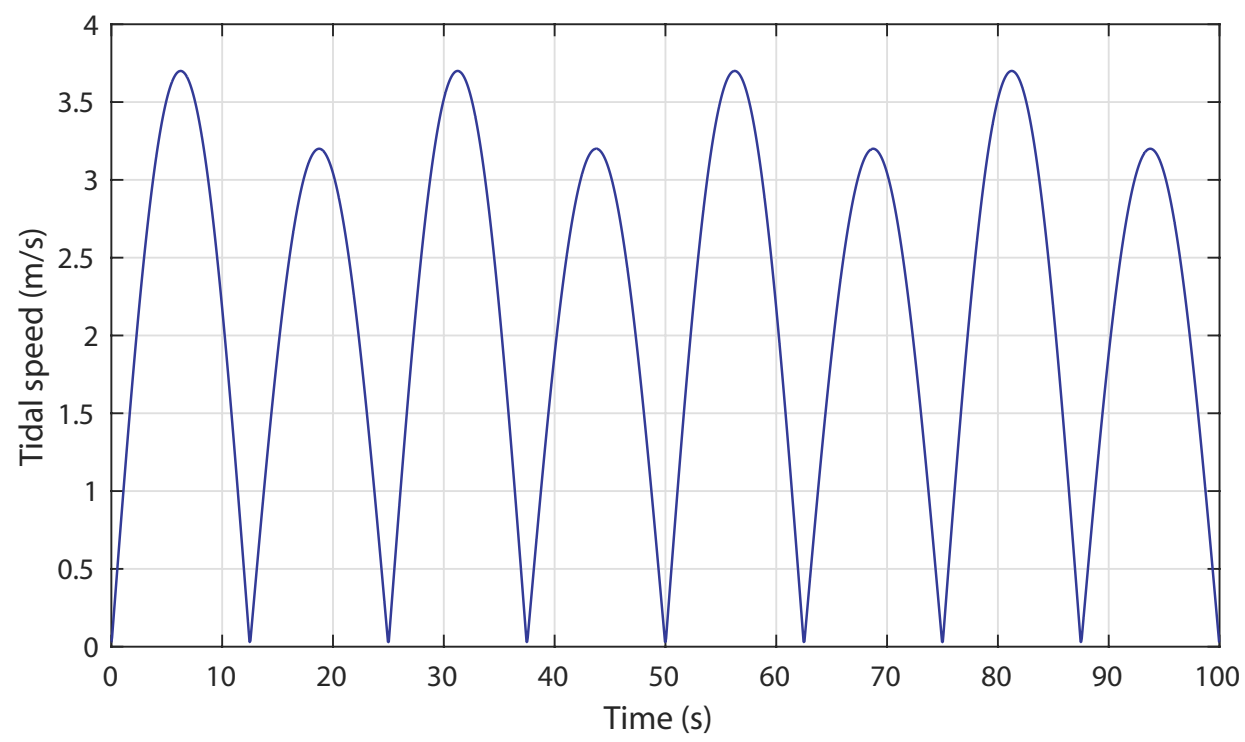

Figure 13. Scenario 1: regular tidal speed input.

(a)

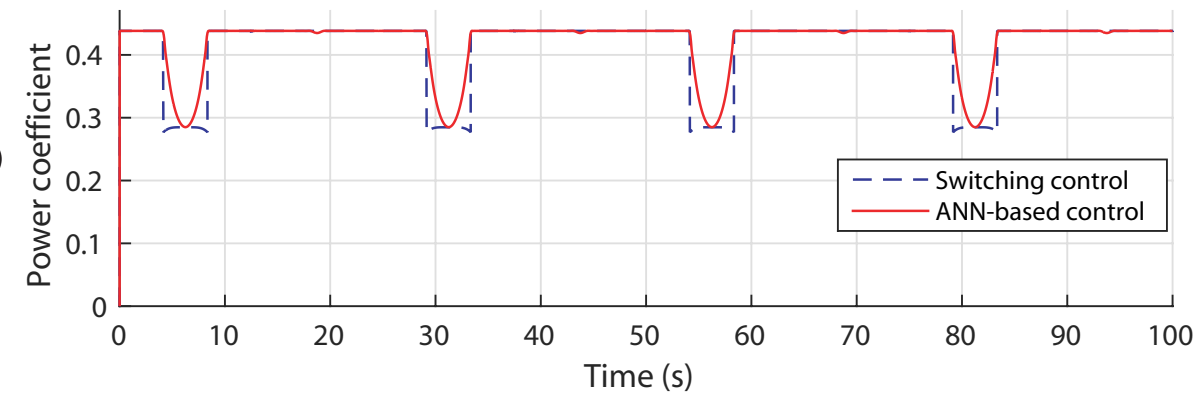

(b)

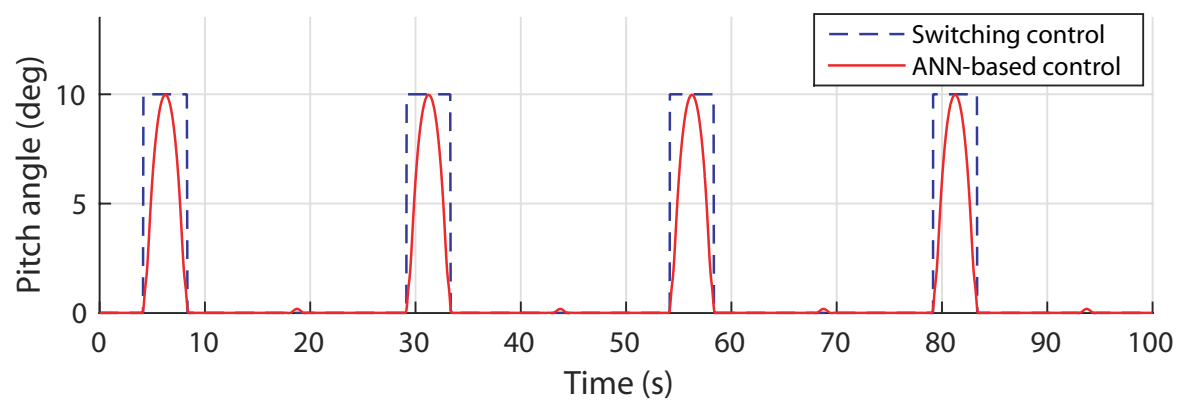

Figure 14. Control performances in scenario 1: (a) power coefficient response; (b) pitch angle response. 


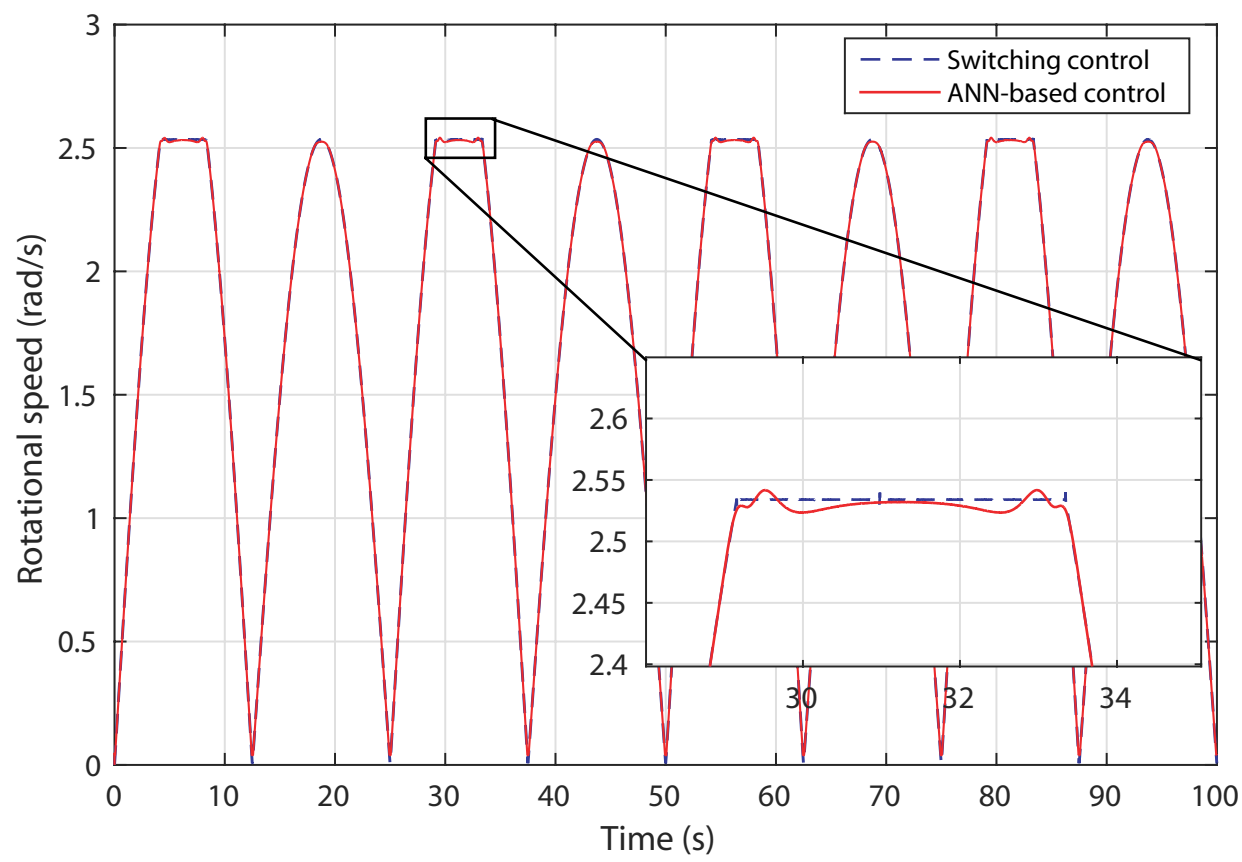

Figure 15. Scenario 1: turbine rotational speed variation.

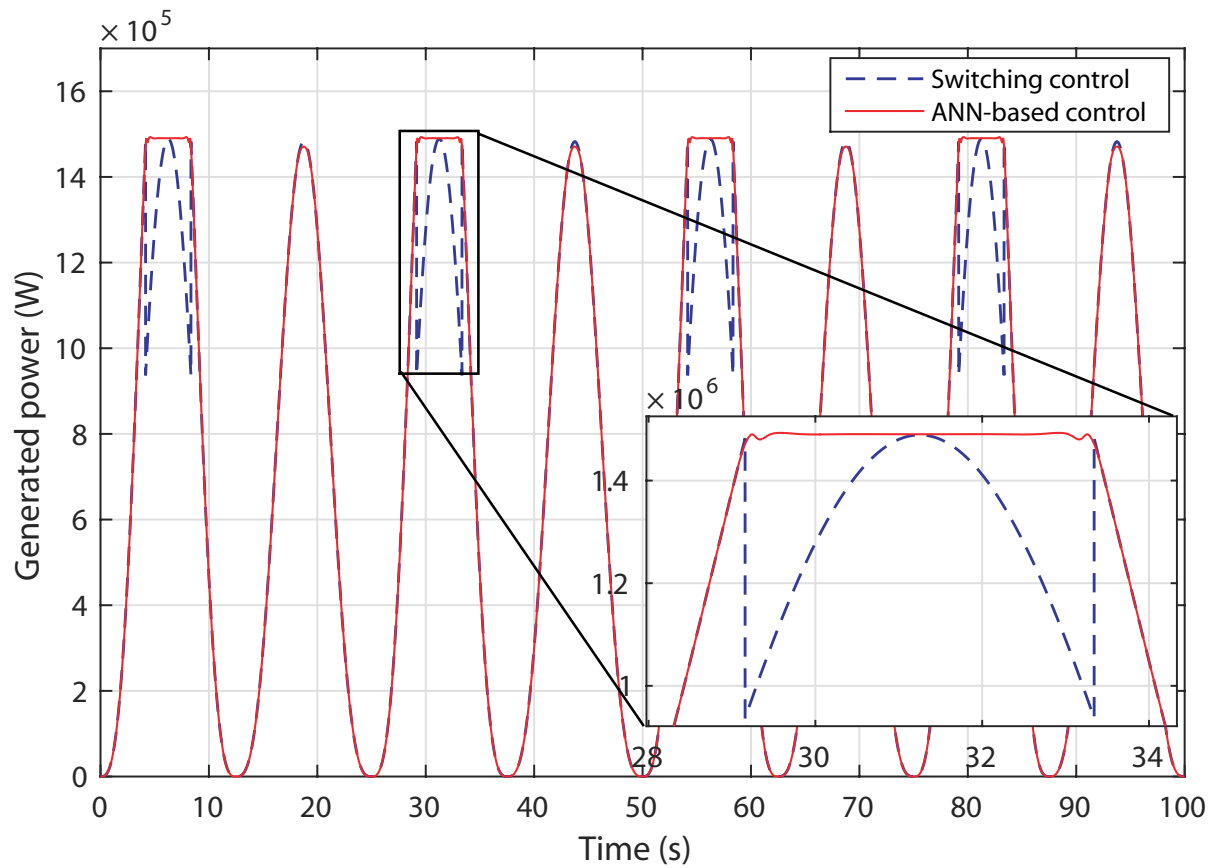

Figure 16. Scenario 1: generated active power variation.

\subsection{Robustness of the ANN-Based Control against Swell Effects}

In this subsection, the proposed ANN control strategy is analyzed regarding the swell effect disturbances. Based on the model previously developed in Section 2, a disturbed tidal resource with a minimum speed of $1.3 \mathrm{~m} / \mathrm{s}$ and a maximum speed of $4.8 \mathrm{~m} / \mathrm{s}$ is set. The turbulent resource characteristic is given in Figure 17.

Figure 18 illustrates the power coefficient and pitch angle responses. In this experiment, it can be seen that the power coefficient response is kept around its optimum value $C_{p}=0.4382$ and adequately 
varies in the case of high tidal velocity. The resulting pitch angle increases accordingly with the tidal speed variation.

Figure 19 illustrates the variation of the rotational speed and the reference obtained with the proposed MPPT strategy. The control system performs well because the rotational speed shows a good tracking performance of the reference signal.

The produced power under swell effect is shown in Figure 20. The proposed control is able to limit the power generated at $P_{n}$ when the tidal current speed exceeds $V_{n}$. The ANN complementary control ensures a smoothing transition between the variable speed mode and the power limitation mode. Simulation results show that the novel control strategy is excellent in terms of speed tracking and power regulation.

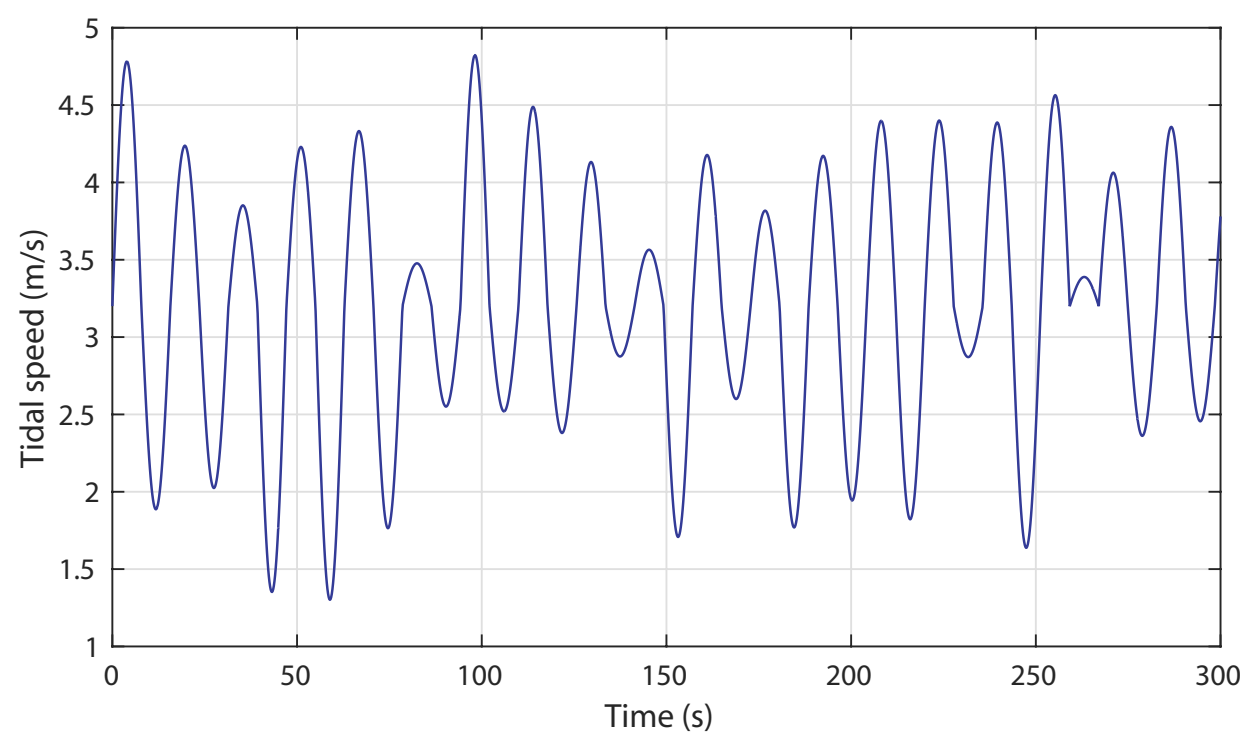

Figure 17. Scenario 2: Turbulent tidal speed input.

(a)

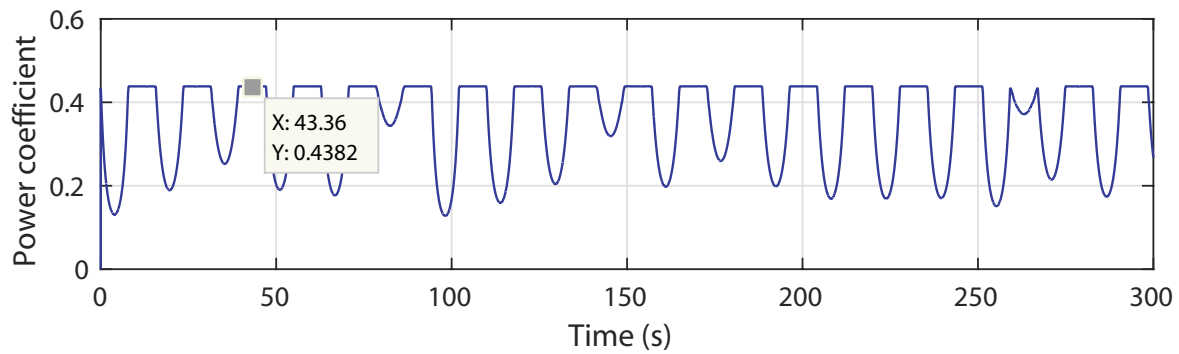

(b)

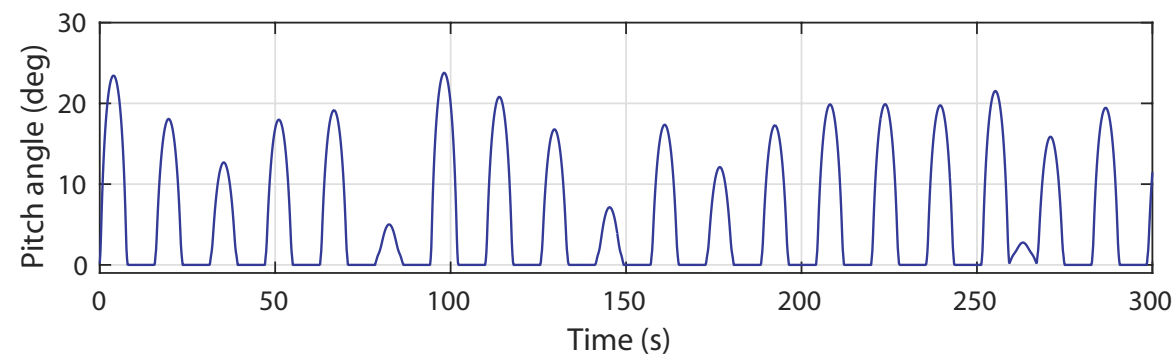

Figure 18. Control performances in scenario 2: (a) power coefficient response; (b) pitch angle response. 


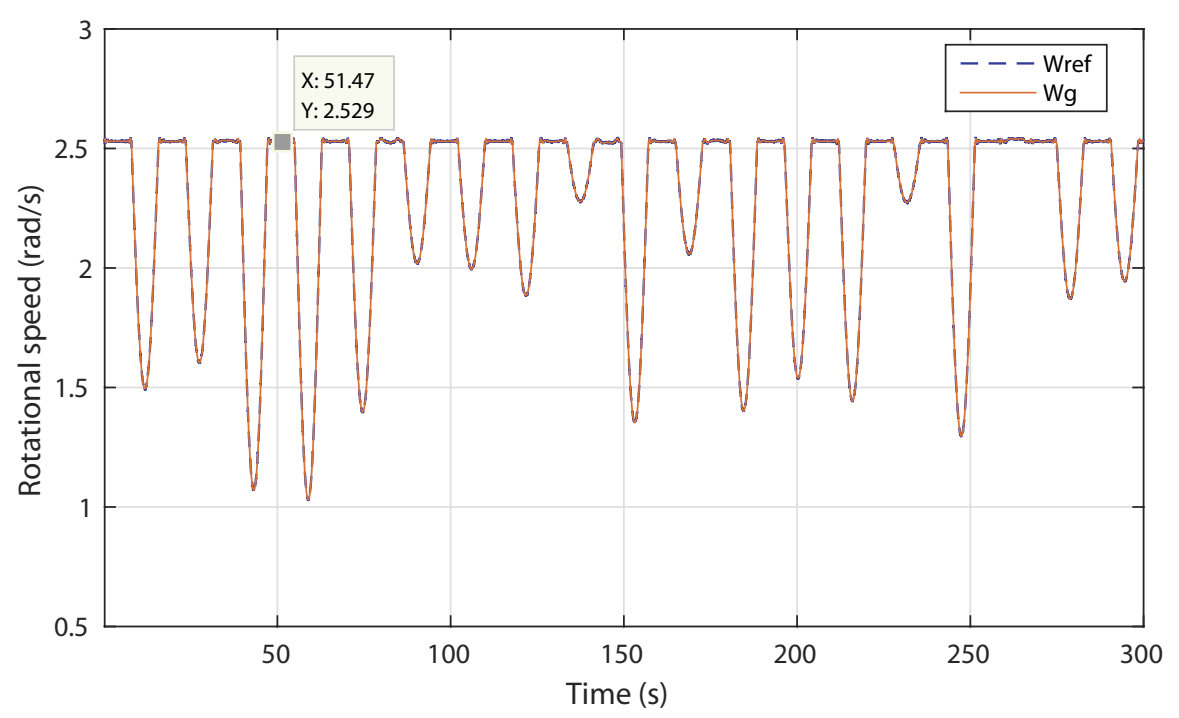

Figure 19. Scenario 2: Generated reference and actual rotational speed.

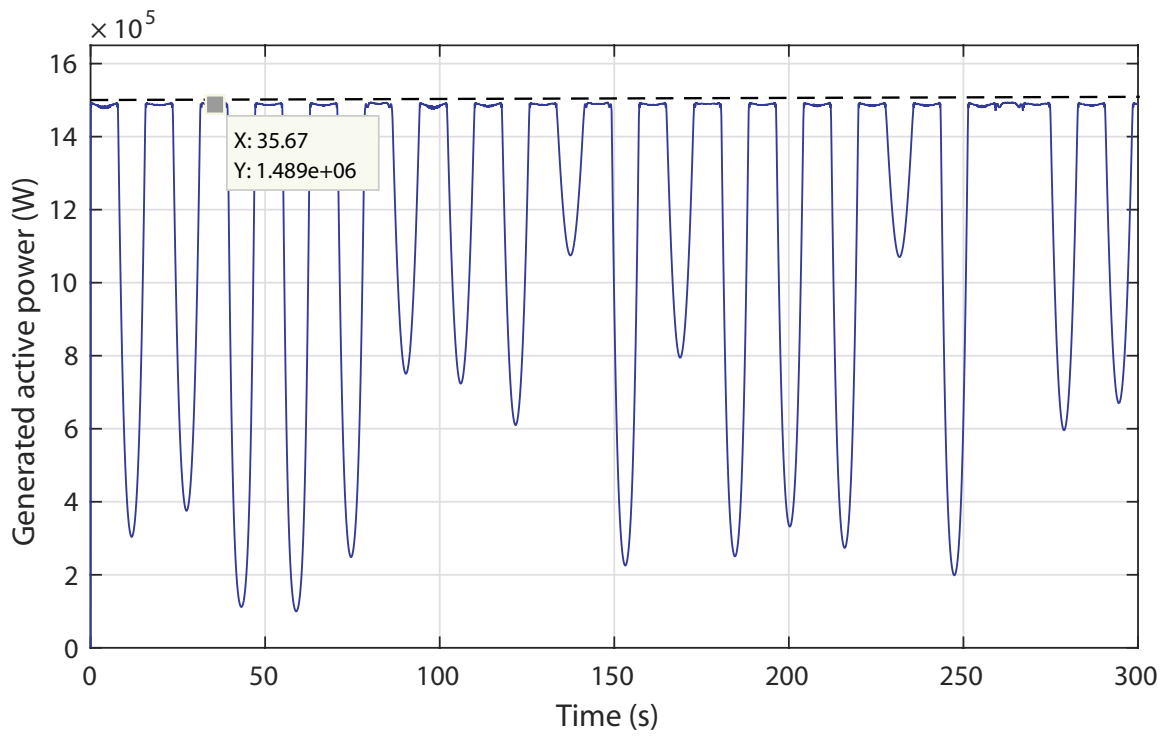

Figure 20. Scenario 2: Generated active power response.

\section{Conclusions}

In this paper, a DFIG-based TST system has been modeled and controlled. Two control strategies have been designed and implemented to deal with the power fluctuations due to the swell effect phenomenon. The first control approach is elaborated around a novel complementary ANN-based MPPT pitch angle control strategy. On one hand, the MPPT approach aims to track the suitable rotational speed in order to achieve the maximum power generation. On the other hand, the pitch angle controller adequately regulates the angular position of the turbine blades in order to limit the extracted power for high tidal current speeds. The second control strategy is devoted to the rotational speed regulation by means of the rotor side and grid side converters. A stator flux-oriented control scheme was applied to the RSC and a voltage-oriented control was used for the GSC. The implemented control scheme aims to alternate between both operation modes. That is, the TSG is regulated so as to smoothly pass from the variable speed mode to the power limitation mode in order to optimize the generated output power and to ensure the protection of the system from overloading. 
To test the effectiveness of the complementary ANN controller, a scenario is proposed with a variable spring and neap tidal current speed. This control strategy was introduced to solve the problems of the switching control. The obtained results prove that the implemented control has an advantage of eliminating the pic at the output signal and that the response time between the variable speed and power limitation modes is reduced. This proposed ANN-based pitch angle control makes the output signal smoother and eliminates signal discontinuity, which is a drawback when applying the conventional proportional controller. By using the proposed novel control strategy, the transition between controls is successfully smoothed given an input variable signal with the shape of the real tidal speed.

A second scenario was carried out to test the robustness of the ANN control strategy against swell effect disturbances. Results prove that the controller successfully overcomes these fluctuations, enabling the TSG system to extract the maximum power. In addition, this control strategy provides an excellent performance and improves the power generation regarding a fluctuated tidal resource.

Author Contributions: All authors contributed to the modeling and implementation of this work. Khaoula Ghefiri conceived, developed and analyzed the control techniques. All authors contributed to writing the manuscript.

Acknowledgments: This work was supported in part by the University of the Basque Country (Universidad del Pais Vasco UPV / Euskal Herriko Unibertsitatea EHU) through Project PPG17/33, by MINECO through the Research Project DPI2015-70075-R (MINECO/FEDER, EU) and by the Basque Goverment through Elkartek.

Conflicts of Interest: The authors declare no conflict of interest.

\section{Appendix A}

Table A1. Levenberg-Marquardt training performances.

\begin{tabular}{|c|c|c|}
\hline Neurons Number in Hidden Layer & Epochs & MSE \\
\hline \multirow{5}{*}{2} & 13 & 0.032676 \\
\hline & 18 & 0.049599 \\
\hline & 21 & 0.036628 \\
\hline & 35 & 0.03845 \\
\hline & 41 & 0.029477 \\
\hline \multirow{7}{*}{5} & 58 & 0.034446 \\
\hline & 70 & 0.0004752 \\
\hline & 153 & 0.00038727 \\
\hline & 187 & 0.00053197 \\
\hline & 225 & 0.00049101 \\
\hline & 326 & 0.000532 \\
\hline & 714 & 0.0001963 \\
\hline \multirow{6}{*}{7} & 69 & 0.00016313 \\
\hline & 138 & 0.00019381 \\
\hline & 222 & 0.0002327 \\
\hline & 653 & 0.00017829 \\
\hline & 751 & 0.00014904 \\
\hline & 1000 & 0.00017071 \\
\hline \multirow{6}{*}{10} & 118 & 0.00012838 \\
\hline & 361 & $9.1106 \times 10^{-5}$ \\
\hline & 649 & $8.7021 \times 10^{-5}$ \\
\hline & 720 & $6.2352 \times 10^{-5}$ \\
\hline & 955 & $4.3441 \times 10^{-5}$ \\
\hline & 1000 & $3.8614 \times 10^{-5}$ \\
\hline \multirow{6}{*}{11} & 115 & 0.00019116 \\
\hline & 157 & 0.00014699 \\
\hline & 241 & 0.00011463 \\
\hline & 623 & $9.5236 \times 10^{-5}$ \\
\hline & 904 & $8.9541 \times 10^{-5}$ \\
\hline & 1000 & $5.3738 \times 10^{-5}$ \\
\hline
\end{tabular}


Table A2. TSG system parameters.

\begin{tabular}{cccc}
\hline Turbine & Drive-Train & DFIG & Converter \\
\hline$\rho=1027 \mathrm{~kg} / \mathrm{m}^{3}$ & $H_{t}=3 \mathrm{~s}$ & $P_{n}=1.5 \mathrm{MW}$ & $V_{d c}=1150 \mathrm{~V}$ \\
$\mathrm{R}=8 \mathrm{~m}$ & $H_{g}=0.5 \mathrm{~s}$ & $U_{r m s}=690 \mathrm{~V}$ & $\mathrm{C}=0.01 \mathrm{~F}$ \\
$C_{p \max }=0.44$ & $K_{s h}=2 \times 10^{6} \mathrm{Nm} / \mathrm{rad}$ & $f_{r e q}=50 \mathrm{~Hz}$ & \\
$\lambda_{\text {opt }}=6.96$ & $D_{s h}=3.5 \times 10^{5} \mathrm{Nms} / \mathrm{rad}$ & $R_{s}=2.63 \mathrm{~m} \Omega$ & \\
$V_{n}=3.2 \mathrm{~m} / \mathrm{s}$ & & $R_{r}=2.63 \mathrm{~m} \Omega$ & Choke \\
& & $L_{s}=0.168 \mathrm{mH}$ & $R_{g}=0.595 \mathrm{~m} \Omega$ \\
& $L_{r}=0.133 \mathrm{mH}$ & $L_{g}=0.157 \mathrm{mH}$ \\
& $L_{m}=5.474 \mathrm{mH}$ & \\
& $p=2$ & \\
\hline
\end{tabular}

\section{References}

1. Remagnino, P.; Foresti, G.L. Ambient intelligence: A new multidisciplinary paradigm. IEEE Trans. Syst. Man Cybern. Part A Syst. Hum. 2005, 35, 1-6.

2. Cook, D.J.; Augusto, J.C.; Jakkula, V.R. Ambient intelligence: Technologies, applications, and opportunities. Pervasive Mob. Comput. 2009, 5, 277-298.

3. Kohonen, T. An introduction to neural computing. Neural Netw. 1988, 1, 3-16.

4. Kalogirou, S.A. Artificial neural networks in renewable energy systems applications: A review. Renew. Sustain. Energy Rev. 2001, 5, 373-401.

5. Garcia, E.; Quiles, E.; Correcher, A.; Morant, F. Sensor Buoy System for Monitoring Renewable Marine Energy Resources. Sensors 2018, 18, 945.

6. Lekube, J.; Garrido, A.J.; Garrido, I.; Otaola, E.; Maseda, J. Flow Control in Wells Turbines for Harnessing Maximum Wave Power. Sensors 2018, 18, 535.

7. Bhattacharya, M.; Paramati, S.R.; Ozturk, I.; Bhattacharya, S. The effect of renewable energy consumption on economic growth: Evidence from top 38 countries. Appl. Energy 2016, 162, 733-741.

8. Couture, T.; Gagnon, Y. An analysis of feed-in tariff remuneration models: Implications for renewable energy investment. Energy Policy 2010, 38, 955-965.

9. Uihlein, A.; Magagna, D. Wave and tidal current energy-A review of the current state of research beyond technology. Renew. Sustain. Energy Rev. 2016, 58, 1070-1081.

10. Magagna, D.; Uihlein, A. Ocean energy development in Europe: Current status and future perspectives. Int. J. Mar. Energy 2015, 11, 84-104.

11. Waters, S.; Aggidis, G. Tidal range technologies and state of the art in review. Renew. Sustain. Energy Rev. 2016, 59, 514-529.

12. Neill, S.P.; Hashemi, M.R.; Lewis, M.J. Tidal energy leasing and tidal phasing. Renew. Energy 2016, 85, 580-587.

13. Ocean Energy Forum, Ocean Energy Europe. Ocean Energy Strategic Roadmap 2016; Building Ocean Energy for Europe: Brussels, Belgium, 2016.

14. World Energy Council. World Energy Resources; Technic Report; World Energy Council: London, UK, 2016.

15. Bryden, I.G.; Couch, S.J. ME1-marine energy extraction: Tidal resource analysis. Renew. Energy 2006, 31, 133-139.

16. Myers, L.; Bahaj, A.S. Simulated electrical power potential harnessed by marine current turbine arrays in the Alderney Race. Renew. Energy 2005, 30, 1713-1731.

17. Hammons, T.J. Tidal power. Proc. IEEE 1993, 81, 419-433.

18. Zhou, Z.; Scuiller, F.; Charpentier, J.F.; Benbouzid, M.E.H.; Tang, T. Power smoothing control in a grid-connected marine current turbine system for compensating swell effect. IEEE Trans. Sustain. Energy 2013, 4, 816-826.

19. Benelghali, S.; Benbouzid, M.E.H.; Charpentier, J.F. Generator systems for marine current turbine applications: A comparative study. IEEE J. Ocean. Eng. 2012, 37, 554-563.

20. Choi, J.S.; Jeong, R.G.; Shin, J.H.; Kim, C.K.; Kim, Y.S. New Control Method of Maximum Power Point Tracking for Tidal Energy Generation System. In Proceedings of the International Conference on Electrical Machines and Systems, Seoul, Korea, 8-11 October 2007; pp. 165-168. 
21. Jahromi, M.J.; Maswood, A.I.; Tseng, K.J. Design and evaluation of a new converter control strategy for near-shore tidal turbines. IEEE Trans. Ind. Electron. 2013, 60, 5648-5659.

22. Liu, C.; Xu, D.; Zhu, N.; Blaabjerg, F.; Chen, M. DC-voltage fluctuation elimination through a DC-capacitor current control for DFIG converters under unbalanced grid voltage conditions. IEEE Trans. Power Electron. 2013, 28, 3206-3218.

23. Ben Elghali, S.E.; Benbouzid, M.E.H.; Charpentier, J.F. Modeling and Control of a Marine Current Turbine Driven Doubly-Fed Induction Generator. IET Renew. Power Gener. 2010, 4, 1-11.

24. Whitby, B.; Ugalde-Loo, C.E. Performance of Pitch and Stall Regulated Tidal Stream Turbines. IEEE Trans. Sustain. Energy 2014, 5, 64-72.

25. Kirke, B.K.; Lazauskas, L. Limitations of fixed pitch Darrieus hydrokinetic turbines and the challenge of variable pitch. Renew. Energy 2011, 36, 893-897.

26. Zhou, Z.; Scuiller, F.; Charpentier, J.F.; Benbouzid, M.; Tang, T. Power limitation control for a PMSG-based marine current turbine at high tidal speed and strong sea state. In Proceedings of the Electric Machines and Drives Conference (IEMDC), Chicago, IL, USA, 12-15 May 2013; pp. 75-80.

27. Lewis, M.J.; Neill, S.P.; Hashemi, M.R.; Reza, M. Realistic wave conditions and their influence on quantifying the tidal stream energy resource. Appl. Energy 2014, 136, 495-508.

28. Amundarain, M.; Alberdi, M.; Garrido, A.J.; Garrido, I.; Maseda, J. Wave energy plants: Control strategies for avoiding the stalling behaviour in the Wells turbine. Renew. Energy 2010, 35, 2639-2648.

29. Zhou, Z.; Benbouzid, M.; Charpentier, J.F.; Scuiller, F.; Tang, T. A review of energy storage technologies for marine current energy systems. Renew. Sustain. Energy Rev. 2013, 18, 390-400.

30. L'étude Porte Sur le Mouvement Ondulatoire Régulier. Available online: http://hmf.enseeiht.fr/travaux/ CD0001/travaux/optsee/hym/7/rapport.htm (accessed on 24 April 2018).

31. Goda, Y. Random Seas and Design of Maritime Structures, 3rd ed.; Advanced Series on Ocean Engineering; World Scientific Publishing Company: Singapore, 2010.

32. Ghefiri, K.; Bouallègue, S.; Garrido, I.; Garrido, A.J.; Haggège, J. Complementary Power Control for Doubly Fed Induction Generator-Based Tidal Stream Turbine Generation Plants. Energies 2017, 10, 862, doi:10.3390/en10070862.

33. Ghefiri, K.; Bouallègue, S.; Garrido, I.; Garrido, A.J.; Haggège, J. Modeling and MPPT control of a Tidal Stream Generator. In Proceedings of the 2017 4th International Conference on Control, Decision and Information Technologies (CoDIT'17), Barcelona, Spain, 5-7 April 2017; pp. 1003-1008.

34. Ghefiri, K.; Bouallègue, S.; Haggège, J. Modeling and SIL simulation of a Tidal Stream device for marine energy conversion. In Proceedings of the 2015 6th International Renewable Energy Congress (IREC), Sousse, Tunisia, 24-26 March 2015; pp. 1-6.

35. Wang, L.; Li, C.N. Dynamic stability analysis of a tidal power generation system connected to an onshore distribution system. IEEE Trans. Energy Convers. 2011, 26, 1191-1197.

36. Fernandez, L.M.; Jurado, F.; Saenz, J.R. Aggregated dynamic model for wind farms with doubly fed induction generator wind turbines. Renew. Energy 2008, 33, 129-140.

37. Inoue, T.; Taniguchi, H.; Ikeguchi, Y.; Yoshida, K. Estimation of power system inertia constant and capacity of spinning-reserve support generators using measured frequency transients. IEEE Trans. Power Syst. 1997, 12, 136-143.

38. Amundarain, M.; Alberdi, M.; Garrido, A.J.; Garrido, I. Modeling and simulation of wave energy generation plants: Output power control. IEEE Trans. Ind. Electron. 2011, 58, 105-117.

39. Alberdi, M.; Amundarain, M.; Garrido, A.J.; Garrido, I.; Maseda, F.J. Fault-ride-through capability of oscillating-water-column-based wave-power-generation plants equipped with doubly fed induction generator and airflow control. IEEE Trans. Ind. Electron. 2011, 58, 1501-1517.

40. Pena, R.; Clare, J.C.; Asher, G.M. Doubly fed induction generator using back-to-back PWM converters and its application to variable-speed wind-energy generation. IEE Proc. Electr. Power Appl. 1996, 143, 231-241.

41. Muller, S.; Diecke, M.; De Donker, R.W. Doubly fed induction generator systems for wind turbines. IEEE Ind. Appl. Mag. 2002, 8, 26-33.

42. Ledesma, P.; Usaola, J. Doubly fed induction generator model for transient stability analysis. IEEE Trans. Energy Convers. 2005, 20, 388-397.

43. Zhou, D.; Blaabjerg, F.; Lau, M.; Tonnes, M. Optimized reactive power flow of DFIG power converters for better reliability performance considering grid codes. IEEE Trans. Ind. Electron. 2015, 62, 1552-1562. 
44. Hu, J.; Nian, H.; Xu, H.; He, Y. Dynamic modeling and improved control of DFIG under distorted grid voltage conditions. IEEE Trans. Energy Convers. 2011, 26, 163-175.

45. Blaabjerg, F.; Iov, F.; Kerekes, T.; Teodorescu, R.; Ma, K. Power electronics-key technology for renewable energy systems. In Proceedings of the Power Electronics, Drive Systems and Technologies Conference (PEDSTC), Tehran, Iran, 16-17 February 2011; pp. 445-466.

46. Alberdi, M.; Amundarain, M.; Garrido, A.J.; Garrido, I.; Casquero, O.; De la Sen, M. Complementary control of oscillating water column-based wave energy conversion plants to improve the instantaneous power output. IEEE Trans. Energy Convers. 2011, 26, 1021-1032.

47. Fletcher, J.; Yang, J. Introduction to the Doubly-Fed Induction Generator for Wind Power Applications. In Paths to Sustainable Energy; INTECH Open Access Publisher: London, UK, 2010.

48. Lei, Y.; Mullane, A.; Lightbody, G.; Yacamini, R. Modeling of the wind turbine with a doubly fed induction generator for grid integration studies. IEEE Trans. Energy Convers. 2006, 21, 257-264.

49. Omidvar, O.; Elliott, D.L. Neural Systems for Control; Academic Press: Cambridge, MA, USA, 1997; ISBN 9780080537399.

50. Yilmaz, A.S.; Ozer, Z. Pitch angle control in wind turbines above the rated wind speed by multi-layer perceptron and radial basis function neural networks. Expert Syst. Appl. 2009, 36, 9767-9775.

51. Alberdi, M.; Amundarain, M.; Garrido, A.; Garrido, I. Neural control for voltage dips ride-through of oscillating water column-based wave energy converter equipped with doubly-fed induction generator. Renew. Energy 2012, 48, 16-26.

52. Munteanu, I.; Bratcu, A.I.; Cutululis, N.; Ceanga, E. Optimal Control of Wind Energy Systems: Towards a Global Approach; Springer: Berlin, Germany, 2008; ISBN 978-1-84800-079-7.

53. Multon, B. Marine Renewable Energy Handbook; British Library Cataloguing-In-Publication Data; John Wiley \& Sons: Hoboken, NJ, USA, 2013; ISBN 978-1-84821-332-6.

54. Sheela, K.G.; Deepa, S.N. Review on methods to fix number of hidden neurons in neural networks. Math. Probl. Eng. 2013, doi:10.1155/2013/425740.

55. Hagan, M.T.; Menhaj, M.B. Training feedforward networks with the Marquardt algorithm. IEEE Trans. Neural Netw. 1994, 5, 989-993.

56. Wilamowski, B.M.; Yu, H. Improved computation for Levenberg-Marquardt training. IEEE Trans. Neural Netw. 2010, 21, 930-937.

57. Suratgar, A.A.; Tavakoli, M.B.; Hoseinabadi, A. Modified Levenberg-Marquardt method for neural networks training. Int. J. Comput. Inf. Eng. 2010, 6, 46-48.

58. Ampazis, N.; Perantonis, S.J. Levenberg-Marquardt algorithm with adaptive momentum for the efficient training of feedforward networks. In Proceedings of the IEEE-INNS-ENNS International Joint Conference on Neural Networks, Como, Italy, 27-27 July 2000; pp. 126-131.

59. Twining, E.; Holmes, D.G. Grid current regulation of a three-phase voltage source inverter with an LCL input filter. IEEE Trans. Power Electron. 2003, 18, 888-895.

60. Astrom, K.J.; Hagglund, T. Advanced Pid Control; ISA-The Instrumentation, Systems, and Automation Society: Research Triangle Park, NC, USA, 2006.

61. Vilanova, R.; Visioli, A. PID Control in the Third Millennium; Springer: London, UK, 2012.

62. Blaabjerg, F.; Teodorescu, R.; Liserre, M.; Timbus, A.V. Overview of control and grid synchronization for distributed power generation systems. IEEE Trans. Ind. Electron. 2006, 53, 1398-1409.

(C) 2018 by the authors. Licensee MDPI, Basel, Switzerland. This article is an open access article distributed under the terms and conditions of the Creative Commons Attribution (CC BY) license (http://creativecommons.org/licenses/by/4.0/). 